\title{
Characterization of Cr-rich Cr-Sb Multilayer Films: Syntheses of a New Metastable Phase Using Modulated Elemental Reactants
}

Matthias Regus ${ }^{1}$, Sergiy Mankovsky ${ }^{2}$, Svetlana Polesya ${ }^{2}$, Gerhard Kuhn ${ }^{2}$, Jeffrey Ditto ${ }^{3}$, Ulrich Schürmann ${ }^{4}$, Alexandre Jacquot ${ }^{5}$, Kilian Bartholomé ${ }^{5}$, Christian Näther ${ }^{1}$, Markus Winkler ${ }^{5}$, Jan D. König ${ }^{5}$, Harald Böttner ${ }^{5}$, Lorenz Kienle ${ }^{4}$, David C. Johnson ${ }^{3}$, Hubert Ebert ${ }^{2}$, Wolfgang Bensch ${ }^{1 *}$

${ }^{1}$ Institute of Inorganic Chemistry, Christian-Albrechts-University of Kiel, Max-Eyth-Str. 2, 24118 Kiel

${ }^{2}$ Department of Chemistry, Ludwig-Maximilians-University Munich, Butenandtstr. 5-13, D-

81377 München, Germany

${ }^{3}$ Department of Chemistry and Materials Science Institute, University of Oregon, 373

Klamath Hall, Eugene, OR 97403, USA

${ }^{4}$ Institute for Materials Science, Christian-Albrechts-University of Kiel, Kaiserstr. 2, 24118

Kiel

${ }^{5}$ Fraunhofer Institute for Physical Measurement Techniques IPM, Thermoelectric Systems, Heidenhofstraße 8, 79110 Freiburg

*email: wbensch@ac.uni-kiel.de, tel: +49 431 880-2419, fax: +49 431 880-1520

\begin{abstract}
The new metastable compound $\mathrm{Cr}_{1+x} \mathrm{Sb}$ with $x$ up to 0.6 has been prepared via a thin film approach using modulated elemental reactants and investigated by in-situ X-ray reflectivity, $\mathrm{X}$-ray diffraction, differential scanning calorimetry, energy dispersive X-ray analysis as well as transmission electron microscopy and atomic force microscopy. The new Cr-rich antimonide crystallizes in a structure related to the $\mathrm{Ni}_{2}$ In-type structure, where the crystallographic position $(1 / 3,2 / 3,3 / 4)$ is partially occupied by excess $\mathrm{Cr}$. The elemental layers of the pristine material interdiffused significantly before $\mathrm{Cr}_{1+x} \mathrm{Sb}$ crystallized. A change in the activation energy was observed for the diffusion process when crystal growth starts. Firstprinciples electronic structure calculations provide insight into the structural stability, magnetic properties and resistivity of $\mathrm{Cr}_{1+x} \mathrm{Sb}$.
\end{abstract}




\section{Key words}

thin film / interdiffusion / metastable phase / in-situ X-ray reflectivity and diffraction / DFT calculation / density of states

\section{Introduction}

Many binary systems, consisting of transition metals (TM) and pnictogenes, like, e.g. $3 d$ transition metal antimonides, shows similarities in their composition and crystal structures. $[1,2]$ According to the phase diagram of the $\mathrm{Cr}-\mathrm{Sb}, \mathrm{Mn}-\mathrm{Sb}$ and $\mathrm{Fe}-\mathrm{Sb}$ systems, only two compounds exist for each binary system. [3-5] Most of the thermodynamically stable $3 d$ metal antimonides with the compositions $\mathrm{MSb}$, where $\mathrm{M}=\mathrm{Ti}, \mathrm{V}, \mathrm{Cr}, \mathrm{Mn}, \mathrm{Fe}, \mathrm{Co}$ and $\mathrm{Ni}$, crystallize in the NiAs-type structure (space group: $P 6_{3} / m m c$ ). [1,6-8] The second compound in each of these phase diagrams is either $\mathrm{MSb}_{2}$ or $\mathrm{M}_{2} \mathrm{Sb}$ crystallizing in the marcasite $\left(\mathrm{CrSb}_{2}\right.$, $\left.\mathrm{FeSb}_{2}\right)$ or $\mathrm{Cu}_{2} \mathrm{Sb}\left(\mathrm{Mn}_{2} \mathrm{Sb}\right)$ structure types. [9, 10] Recently, an additional compound of the composition $\mathrm{Mn}_{3} \mathrm{Sb}$ (space group: $\mathrm{Pm} 3 ;^{-} \mathrm{m}$ ) was synthesized applying thermobaric treatment. [11]

In MnSb the Mn content can be increased $\left(\mathrm{Mn}_{1+x} \mathrm{Sb}, 0<x<1\right)$ thus forming the $\mathrm{Ni}_{2}$ In-type structure, where the atomic position $(1 / 3,2 / 3,3 / 4)$ of the NiAs-type structure is occupied by the additional $\mathrm{Mn}$ atoms. [12] In fact, higher transition metal contents in non-stoichiometric $\mathrm{M}_{1+x} \mathrm{Sb}$ were reported for $\mathrm{M}=\mathrm{Fe}$, Ni and $\mathrm{Co}$ at about $600{ }^{\circ} \mathrm{C}$ to $1000{ }^{\circ} \mathrm{C}$, e.g. with $x$ up to 0.44 for $\mathrm{Fe}$ [1]. From the classical high-temperature synthesis no $\mathrm{Cr}$-rich $\mathrm{Cr}_{1+x} \mathrm{Sb}$ compound crystallizing in the $\mathrm{Ni}_{2} \mathrm{In}$-type is known and only a very small homogeneity range with a maximum $\mathrm{Cr}$ content of 52 at-\% was reported for $\mathrm{CrSb}$. For $\mathrm{M}=\mathrm{Fe}, \mathrm{Ni}$ and $\mathrm{Co}$, the homogeneity range at room temperature is also small with only a few at-\%. [1] The extended composition range at high temperature, however, leads us to speculate that the $\mathrm{Cr}$-Sb system may contain a Cr-rich metastable phase, potentially with a crystal structure considered as $\mathrm{Ni}_{2}$ In-type (see Figure 1).
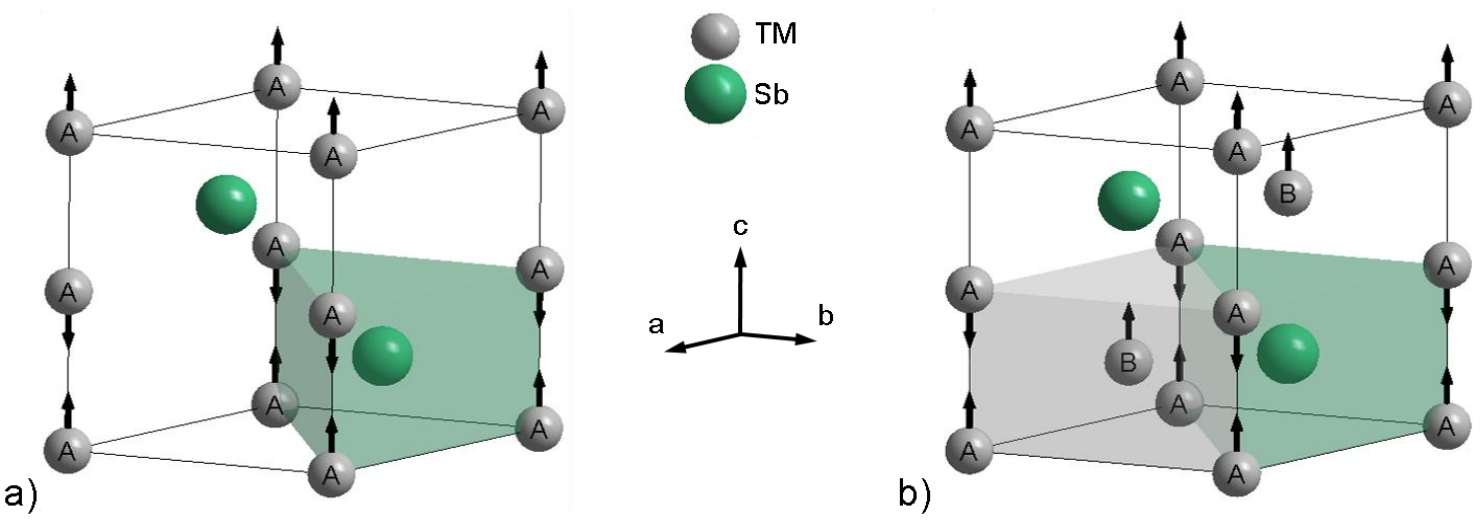

Figure 1: Crystal structure of NiAs [13], which is commonly adopted in $3 d$ transition metal (TM) monoantimonides (a). In $\mathrm{Ni}_{2}$ In-type structure, the crystallographic position $(1 / 3,2 / 3,3 / 4)$ can be partially occupied by an additional transition metal (b) [14]. The arrows represent the magnetic moment of the $\mathrm{Cr}_{\mathrm{A}}$ and $\mathrm{Cr}_{\mathrm{B}}$ atoms as discussed in section 3.8 Interatomic exchange interactions. 
In order to prepare the $\mathrm{Cr}$-rich $\mathrm{Cr}$-Sb compound we decided to apply a thin film approach using modulated elemental reactants (MER), where the constituent elements are deposited alternately on inert substrate and annealed during X-ray investigations. The MER approach has been used successfully for the synthesis of new, metastable compounds. [15-20] This technique was also previously used to explore metastable transition metal antimonides as well as various other binary and ternary compounds based on $\mathrm{Cr}-\mathrm{Sb}, \mathrm{Fe}-\mathrm{Sb}, \mathrm{Ru}-\mathrm{Sb}, \mathrm{Ni}-\mathrm{Sb}$ or $\mathrm{Cu}-$ Cr-Se, [21-30] making this a promising approach to the targeted compound.

\section{Experimental and computational details}

\subsection{Deposition}

Multilayered films of $\mathrm{Cr}$ and $\mathrm{Sb}$ in a ratio up to 3:1 were deposited by thermal evaporation of single elements (Cr: ChemPur 99.98\% and Sb: Aldrich 99.999\%) in an ultra-high vacuum chamber with a base pressure of $\mathrm{p}<1 \times 10^{-8}$ mbar on $2 \times 2 \mathrm{~cm}(100)-\mathrm{Si}$ single crystal and $\mathrm{SiO}_{2^{-}}$ substrates. For preparing the multilayer films the single layer thickness was adjusted by the shutter opening times of each evaporation cell, while the effusion cell for $\mathrm{Cr}$ was heated at $1350{ }^{\circ} \mathrm{C}$ and for $\mathrm{Sb}$ at $370{ }^{\circ} \mathrm{C}$. The evaporation rate was determined by a quartz monitor before and after deposition. Liquid nitrogen cooling was applied to the substrate during the deposition process $\left(\mathrm{T}_{\mathrm{Sub}} \approx-45^{\circ} \mathrm{C}\right)$. Including the substrate the samples can be described as [Si/native $\left.\mathrm{SiO}_{x} /(\mathrm{Cr} / \mathrm{Sb})_{\mathrm{m}}\right]$. After deposition the samples were divided into four equal sections of $1 \times 1 \mathrm{~cm}^{2}$ for further investigation.

\subsection{X-ray investigation}

The X-ray reflectivity and diffraction investigations (XRR, XRD) were carried out on a PANalytical X'Pert Pro diffractometer (CuKa radiation, Göbel mirror at the incident beam, PIXel detector) The step size was set to $0.005^{\circ}$ for XRR measurements, $0.04^{\circ}$ for XRD pattern for refinement and $0.08^{\circ}$ for in-situ XRD. XRR measurements were used to determine the repeating unit thickness and the total thickness of the films after deposition and to monitor the interdiffusion of the single elemental layers at elevated temperatures.

The crystallization process of the amorphous samples was investigated by temperatureresolved and isothermal in-situ X-ray diffractometry. All in-situ measurements were carried out in a high temperature chamber (Anton Paar, HTK 1200N) under Helium atmosphere. The temperature was increased in steps of $10{ }^{\circ} \mathrm{C}$ or $2{ }^{\circ} \mathrm{C}$, respectively, with a heating rate of $2{ }^{\circ} \mathrm{C} / \mathrm{min}$ and held at constant temperature during the measurements.

The software TOPAS was used for all Rietveld refinements applying the fundamental parameter approach, spherical harmonics to model preferred orientation and the crystallite size effect [31-35]. The refined parameters were: zero point, scale factors for each phase, lattice parameters of each phase, size broadening, background and occupancy factor for $\mathrm{Cr}$ in the hexagonal phase. For $\mathrm{Cr}_{1+x} \mathrm{Sb}$ (space group: $P 6_{3} / m m c$ ) all atoms are on special positions. 


\subsection{Scanning electron microscopy}

The chemical composition of the films was determined in a scanning electron microscope (SEM, Philips ESEM XL30) by energy dispersive X-ray spectroscopy (EDX, EDAX detector, Oxford Instruments). EDX spectra were recorded at multiple spots of the film in the asdeposited state as well as after the annealing procedure. The ratio of $\mathrm{Cr}$ and $\mathrm{Sb}$ was calculated using the signals of $\mathrm{Cr}-\mathrm{K}$ and $\mathrm{Sb}-\mathrm{L}$ shells. The acceleration voltage of the electron beam was set to $15 \mathrm{keV}$ to reduce the intensity of the Si signal from the substrate. A SEM (SEM: Zeiss Ultra55Plus with FE-Cathode, EDX: Oxford Instruments X-act-Detektor) was used for imaging the surface of the thin films with higher resolution and to perform a line scan for more detailed analyses.

\subsection{Differential Scanning Calorimetry}

A further sample was prepared on a PMMA coated Si substrate for differential scanning calorimetry (DSC) measurements using a DSC 1 Star System with the software package STARe Excellence (Mettler-Toledo AG). The multilayered film consisted of 855 repeating units $(\sim 1300 \mathrm{~nm})$ in order to achieve a sufficient amount of sample for the measurement. After deposition the film was removed from a $1 \times 1 \mathrm{~cm}$ substrate by dissolving PMMA in acetone and washing with pure methanol. The removed film $(0.611 \mathrm{mg})$ was transferred into an Al pan and dried prior to weighting. The DSC measurement was performed in the temperature range from 25 to $600{ }^{\circ} \mathrm{C}$ with a heating rate of $5 \mathrm{~K} / \mathrm{min}$.

\subsection{Atomic force microscopy}

An atomic force microscope (Park Scientific Instrument) was used in conduct mode with silicon probes (Budget Sensors, ContAl-G). The quality of the tips was checked by scanning a gold standard prior to the scans on the as deposited and annealed films. The surface roughness and an image of the topography of the samples in different states were extracted from the scans. A blank Si substrate was scanned and the surface roughness was calculated to be 2.1(1) $\AA$.

\subsection{Transmission electron microscopy}

The sample preparation for TEM was done by focused ion beam (FIB) milling. Two lamellae were cut out of sample MR118_2, which was annealed at $300{ }^{\circ} \mathrm{C}$ prior to preparation containing the crystalline phase $\mathrm{Cr}_{1.5} \mathrm{Sb}$.

Electron diffraction (ED), high resolution TEM (HRTEM) and EDX measurements were performed in a Tecnai F30 G2-STwin microscope at $300 \mathrm{kV}(\mathrm{CS}=1.2 \mathrm{~mm})$ with a field emission gun cathode and a $\mathrm{Si} / \mathrm{Li}$ detector for nanoprobe EDX. EDX elemental mappings were carried out in high angle annular dark field (HAADF) scanning TEM (STEM) mode. HRTEM micrographs were evaluated with the program Digital Micrograph 3.6.1 (Gatan). 


\subsection{Physical property measurements}

Temperature dependent measurements of physical properties like specific resistivity and Halleffect of the annealed films were performed by the van der Pauw method using a physical property measurement system (PPMS, Quantum Design). Copper wires with a diameter of $50 \mu \mathrm{m}$ were connected with conductive silver onto the corners of the films. The measurements were done from $310 \mathrm{~K}$ to $2 \mathrm{~K}$ and back to $310 \mathrm{~K}$ applying a current of $100 \mu \mathrm{A}$. A magnetic field of $\mathrm{B}=0.2 \mathrm{~T}$ was applied during the Hall-measurement.

The Seebeck coefficient was measured in-plane by a homebuilt setup calibrated with a $\mathrm{Ni}$ reference. The measurement uncertainty was $\sim 5 \%$. A temperature difference was applied across the sample while the Seebeck voltage and the temperature difference ( $\sim 3-5 \mathrm{~K})$ between them was measured simultaneously using two thermocouples type T. For the temperature dependent electrical measurements of the Seebeck coefficient (measurement uncertainty ca. $7 \%$ ) and the electrical conductivity (uncertainty ca. 10\%) the setup SRX developed by Fraunhofer IPM was used. [36] The sample chamber was evacuated and then kept under a nitrogen pressure of 100 mbar during the measurement.

\subsection{Computational details}

The electronic structure calculations have been done using the full-potential KKR (KorringaKohn-Rostoker) Green function method [37,38]. Exchange and correlation were treated within the framework of GGA using the Perdew, Burke, Ernzerhof (PBE) parametrization [39]. A regular k-mesh of $33 \times 33 \times 22$ points in the full $3 \mathrm{D}$ Brillouin Zone (BZ) was used for the k-space integration. For the angular momentum expansion of the Green's function a cutoff of $l_{\text {max }}=3$ was applied. The exchange coupling parameters $J_{i j}$ have been calculated using the so-called Lichtenstein expression on the basis of the magnetic force theorem [40].

\section{Results and Discussion}

\subsection{X-ray reflectivity and $\mathrm{X}$-ray diffraction}

The total film thickness as well as the repeating unit thickness, consisting of elemental $\mathrm{Cr}$ and $\mathrm{Sb}$ layers, was determined from low angle X-ray patterns using the position of the Kiessigfringes or satellite maxima. Figure 2 displays an XRR curve of a multilayer film (MR76_2, Table 1) in the as-deposited state with a repeating unit of $16.7 \AA$ showing the $1^{\text {st }}$ and $2^{\text {nd }}$ order satellite maximum only. More details, like e.g. composition and repeating unit thickness of the samples used in the present study are summarized in Table 1. It must be noted that a variation in thickness and composition of the films was observed by XRR and EDX analysis, which originates in the different orientation of the substrate relative to the $\mathrm{Cr}$ and $\mathrm{Sb}$ effusion cells, respectively. 


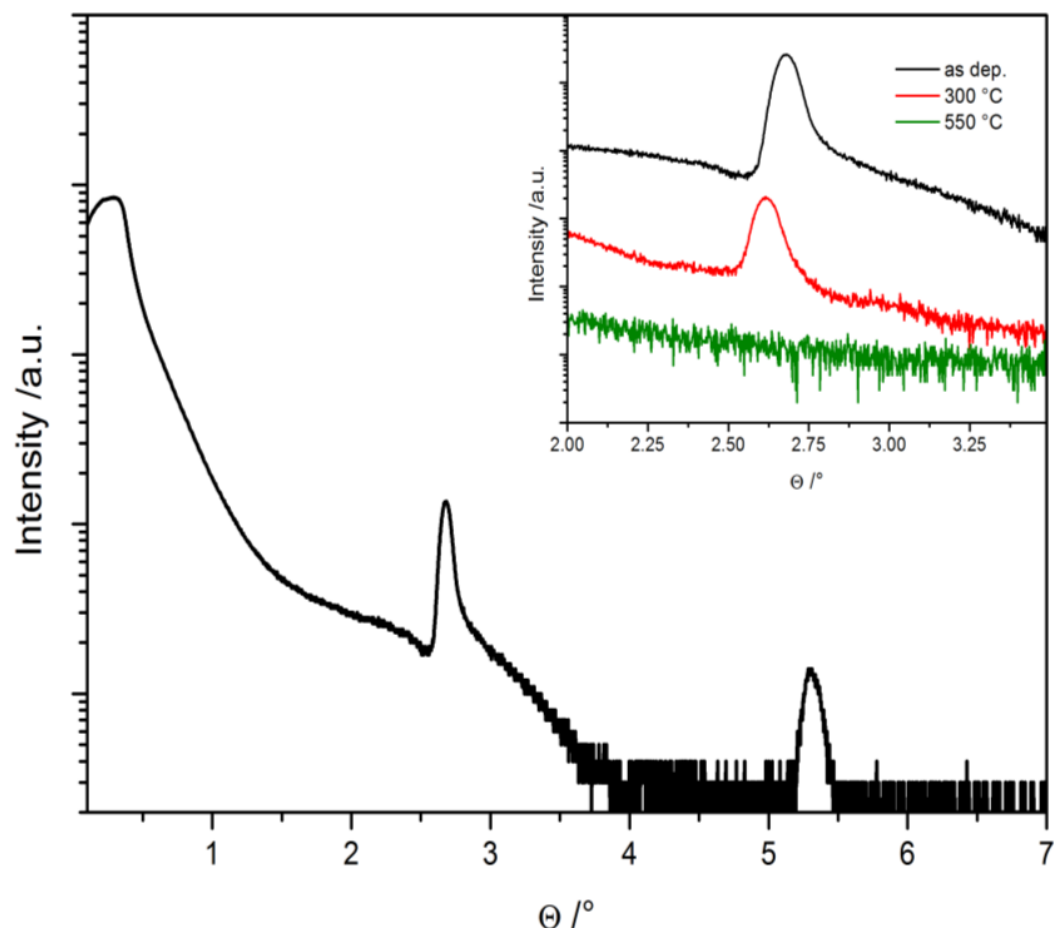

Figure 2: XRR curve of a multilayer film with 59 at-\% $\mathrm{Cr}$ and a repeating unit of $16.7 \AA$ (MR76_2) in the asdeposited state. Inset: $1^{\text {st }}$ order satellite maximum of the XRR curve at elevated temperatures.

Table 1: Details of the multilayered film samples including the observed crystal phase and annealing temperatures. Deviations of the composition and the repeating unit thickness were estimated on the basis of the EDX data and the XRR curves.

\begin{tabular}{|c|c|c|c|c|c|c|}
\hline sample & $\begin{array}{l}\text { Cr content } \\
\text { / at- } \%\end{array}$ & $\mathrm{~m}$ & $\begin{array}{c}\text { repeating } \\
\text { unit } \\
/ \AA\end{array}$ & $\begin{array}{l}\text { film thickness } \\
\text { /nm }\end{array}$ & obs. Phase $(s)^{1}$ & $\begin{array}{c}\text { annealing } \\
{ }^{\circ} \mathrm{C}\end{array}$ \\
\hline MR28_1 & $73(5)$ & 65 & $18.8(5)$ & 122.4 & $\mathrm{Cr}_{\sim 1.5} \mathrm{Sb}$ & 300 \\
\hline MR33_1 & $61(5)$ & 135 & $10.3(5)$ & 139.1 & $\mathrm{CrSb}$ & 300 \\
\hline MR33_2 $2^{[21]}$ & $53(5)$ & 135 & $11.4(5)$ & 153.9 & $\mathrm{CrSb}$ & 300 \\
\hline MR34_1 & $60(5)$ & 135 & $10.8(5)$ & 145.8 & $\mathrm{Cr}_{\sim 1.1} \mathrm{Sb}$ & 300 \\
\hline MR34_3 & $62(5)$ & 135 & $11.2(5)$ & 151.0 & $\mathrm{Cr}_{\sim 1.1} \mathrm{Sb}$ & 300 \\
\hline MR35_4 & $68(5)$ & 95 & $15.4(5)$ & 146.7 & $\mathrm{Cr}_{\sim 1.4} \mathrm{Sb}$ & 300 \\
\hline MR36_1 & $72(5)$ & 95 & $13.8(5)$ & 130.6 & $\mathrm{CrSb}+\mathrm{Cr}$ & 550 \\
\hline MR36_3 & $72(5)$ & 95 & $14.0(5)$ & 133.1 & $\mathrm{Cr}_{\sim 1.6} \mathrm{Sb}$ & 262 \\
\hline MR36_4 & $70(5)$ & 95 & $15.7(5)$ & 149.5 & $\mathrm{Cr}_{\sim 1.4} \mathrm{Sb}$ & 300 \\
\hline MR65_2 & $73(5)$ & 885 & N.A. & $\sim 1300^{2}$ & \multicolumn{2}{|c|}{ on PMMA for DSC } \\
\hline MR76_2 & $59(5)$ & 75 & $16.7(5)$ & 125.1 & $\begin{array}{c}\mathrm{CrSb} \\
\mathrm{CrSb}_{2}+\mathrm{Sb}+\mathrm{Cr}\end{array}$ & $\begin{array}{l}300 \\
550\end{array}$ \\
\hline MR111_2 & $72(5)$ & 95 & $10.5(5)$ & 99.8 & $\mathrm{Cr}_{\sim 1.5} \mathrm{Sb}$ & 300 \\
\hline MR111_4 & $72(5)$ & 95 & $10.9(5)$ & 103.6 & $\mathrm{Cr}_{\sim 1.3} \mathrm{Sb}$ & 300 \\
\hline MR118_2 & $72(5)$ & 100 & $18.0(5)$ & 216.1 & $\mathrm{Cr}_{\sim 1.5} \mathrm{Sb}$ & 300 \\
\hline MR119_1 & $72(5)$ & 100 & $15.7(5)$ & 188.0 & N.A. & 570 \\
\hline
\end{tabular}

parameters for deposition as applied for MR36 
All samples are amorphous in the as-deposited state which can be seen in the XRD patterns recorded from $20^{\circ}$ to $50^{\circ} 2 \theta$ (Figure 3). Only broad modulations between $27^{\circ}$ and $33^{\circ} 2 \theta$ and from $37^{\circ}$ to $47^{\circ} 2 \theta$ are observed in the patterns at room temperature. In order to get an overview of the solid state reactivity of a film consisting of a $\mathrm{Cr}-\mathrm{Sb}$ repeating unit thickness of $13.8 \AA$ and a $\mathrm{Cr}$ content of 72 at-\% (MR36_1), a temperature-resolved in-situ XRD experiment between room temperature and $550{ }^{\circ} \mathrm{C}$ was performed (Figure 3). Up to $260{ }^{\circ} \mathrm{C}$ the sample remains amorphous. A hexagonal phase, similar to thermodynamically stable $\mathrm{CrSb}$ (space group: $P 6_{3} / \mathrm{mmc}$ ), crystallizes starting at $270{ }^{\circ} \mathrm{C}$ which transforms into stoichiometric $\mathrm{CrSb}$ and crystalline $\mathrm{Cr}$ (space group: $\operatorname{Im} 3 ;^{-} \mathrm{m}$ ) on further heating. Above $450{ }^{\circ} \mathrm{C}$ the excess of $\mathrm{Cr}$ is detected by the weak (110) reflection of $\mathrm{Cr}$ located at $44.1^{\circ} 2 \theta$ (see also Figure $\mathrm{S} 1$ ). However, the new hexagonal phase and $\mathrm{CrSb}$ coexists over about $50{ }^{\circ} \mathrm{C}$, indicated by the temperature dependent shift of the (102) reflections at $41.9^{\circ}\left(\mathrm{Cr}_{1.6} \mathrm{Sb}\right)$ and $40.4^{\circ}(\mathrm{CrSb})$ as well as the (110) reflection at $43.4^{\circ}\left(\mathrm{Cr}_{1.6} \mathrm{Sb}\right)$ and $44.7^{\circ}(\mathrm{CrSb}) 2 \theta$ of both phases. An EDX measurement performed after the in-situ XRD experiment does not show a significant change in the overall $\mathrm{Cr}: \mathrm{Sb}$ ratio of the film (after annealing: $71(5)$ at-\% $\mathrm{Cr}$ ).

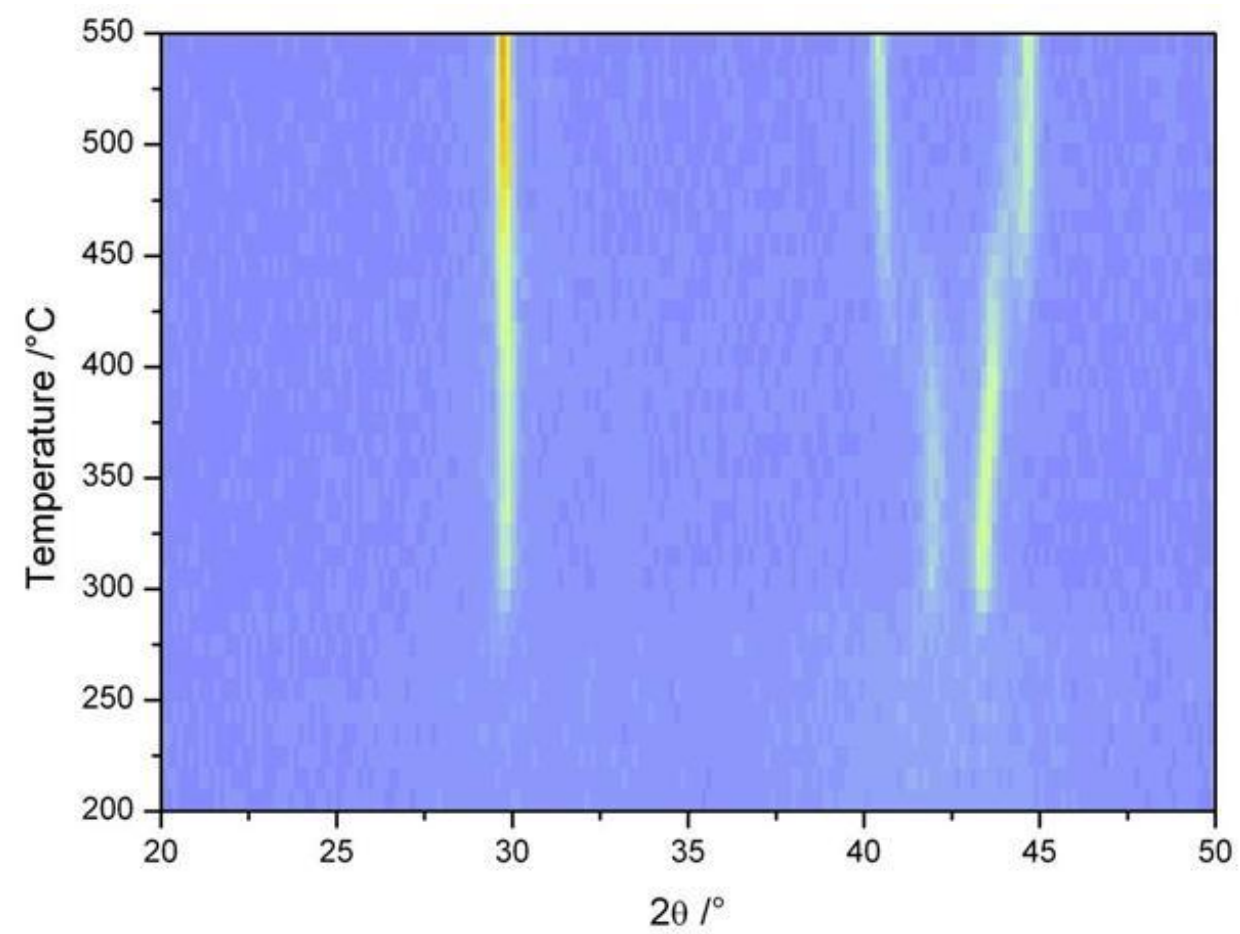

Figure 3: Temperature-dependent in-situ X-ray diffraction patterns of a multilayered film (MR36_1) with a repeating unit of $13.8 \AA$ and a $\mathrm{Cr}$ content of 72 at-\%. The sample was heated with $2{ }^{\circ} \mathrm{C} / \mathrm{min}$ from room temperature to $550{ }^{\circ} \mathrm{C}$ in steps of $10^{\circ} \mathrm{C}$.

In order to understand the reaction mechanism of Cr-rich multilayer films, the intensity of the $1^{\text {st }}$ order satellite maximum, corresponding to the modulation of the elemental layers, as well as the $(101)$ reflection at $29.83^{\circ} 2 \theta(\mathrm{d}=2.99 \AA)$, which does not interfere with other reflections, were monitored during further temperature-dependent in-situ X-ray experiments. Therefore samples with different $\mathrm{Cr}: \mathrm{Sb}$ ratios (59 to 73 at-\%) and different repeating unit 
thicknesses (10.3 to $15.7 \AA$ ) were annealed under inert gas atmosphere. Both, XRR and XRD measurements were performed from room temperature to $300{ }^{\circ} \mathrm{C}$ where interdiffusion and/or crystallization is considered to occur (Figure 4). At room temperature the multilayered films show a very intense $1^{\text {st }}$ order Bragg maximum. Almost no change in intensity of the Bragg reflection occurs at lower temperatures for Cr-richer samples (MR111_2 and MR36_4). The thinner multilayered films containing less Cr (MR33_1, $10.3 \AA$ and 61 at-\% Cr) interdiffused quickly below $75{ }^{\circ} \mathrm{C}$. In contrast, for films with higher $\mathrm{Cr}$ content and independent on the repeating unit thickness, interdiffusion occurs slowly over a very broad temperature range expressed by only a slight change in intensity of the Bragg maxima. Up to $150^{\circ} \mathrm{C}$ all samples stay amorphous as it can be expected from the initial in-situ XRD experiment shown in Figure 3. At $140{ }^{\circ} \mathrm{C}$ the multilayered film (MR34_1) with 61 at-\% $\mathrm{Cr}$ and double layer thickness of $\sim 10 \AA$ crystallizes from the amorphous intermediate and interdiffusion of the layers as well as crystallization of the compound is completed at $\sim 170{ }^{\circ} \mathrm{C}$. The Cr-rich sample with thinner layers starts to crystallize at $160{ }^{\circ} \mathrm{C}\left(\mathrm{MR} 111 \_4,72\right.$ at-\% $\mathrm{Cr}$ and $\left.10.9 \AA\right)$, where the elemental layers interdiffused only partially. However, the $\mathrm{Cr}$-rich sample with a repeating unit of 15.7 $\AA$ (MR36_4, 70 at-\% Cr) interdiffused almost completely before the hexagonal phase $\mathrm{Cr}_{1.6} \mathrm{Sb}$ starts to crystallize at about $220{ }^{\circ} \mathrm{C}$ similar to the results from the $\mathrm{Cr}$-rich sample with a thicker repeating unit shown in Figure 3. All these experiments indicate that the interdiffusion strongly depends on the $\mathrm{Cr}$ content but is not affected by the repeating unit thicknesses, whereas for the crystallization process an opposite trend was observed.

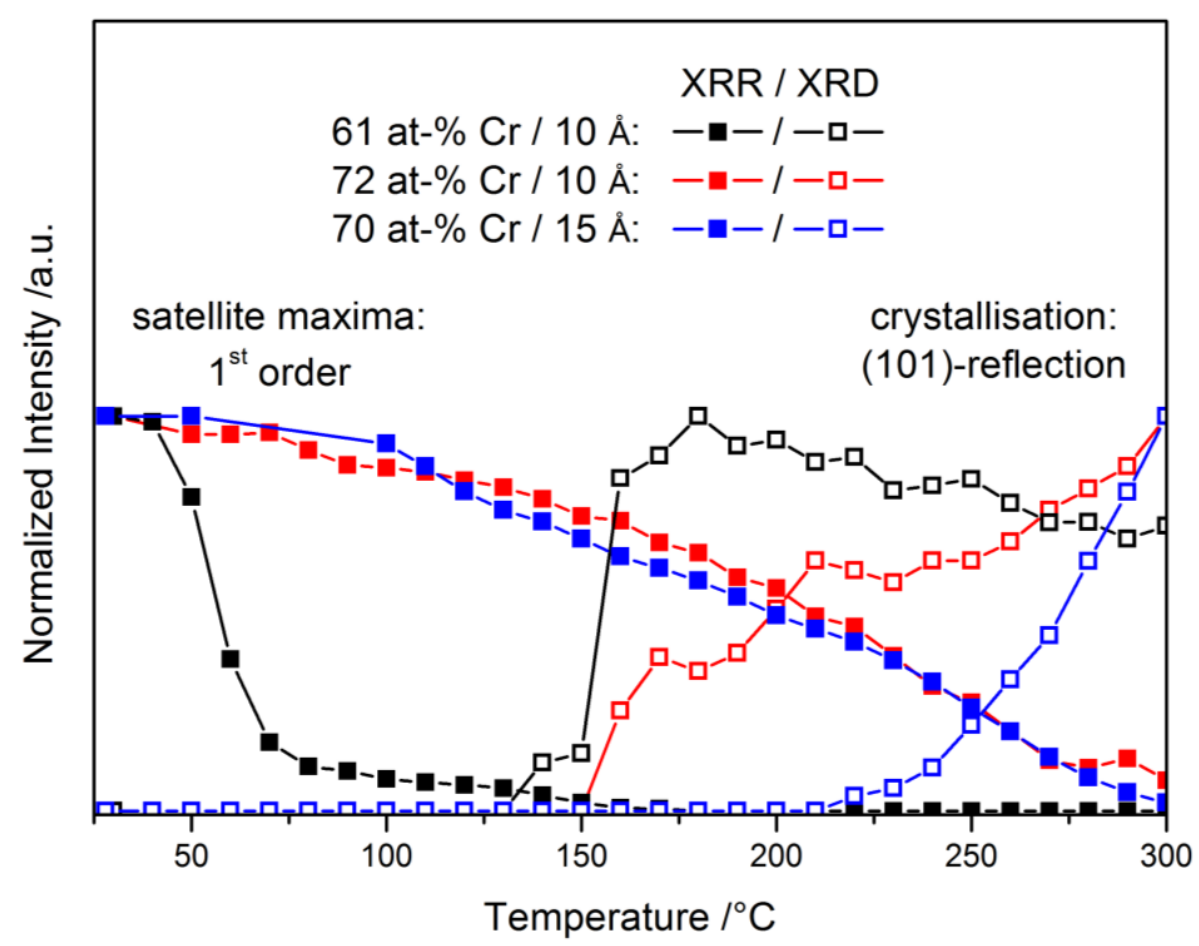

Figure 4: Normalized intensities of the $1^{\text {st }}$ order Bragg maximum and the (101) reflection for different films as function of temperature showing the interdiffusion of the elemental layer and the crystallization of the hexagonal phase, respectively. The intensities were extracted from in-situ XRR (filled) and XRD (open dot) experiments. The lines are a guide for the eye. 
More details become clear when the activation energy is calculated applying the Arrhenius equation to linear regions in both data sets, XRR and XRD. The activation energy is in general significantly lower for interdiffusion of the pure amorphous elemental layers compared to partial crystalline ones received after initial heating (see Table 2). For instance, the amorphous Cr-rich sample with a repeating unit of $15.7 \AA$ (MR36_4) interdiffused significantly before crystallization, which is related to a very low activation energy of $\mathrm{E}_{\mathrm{A} 1 \text {,Diff }}$ $\approx 0.1 \mathrm{eV}$. When crystal growth has started the activation energy for diffusion increases up to $\mathrm{E}_{\mathrm{A} 2 \text {, Diff }} \approx 1.3 \mathrm{eV}$ as the $\mathrm{Cr}$ or $\mathrm{Sb}$ atoms, respectively, have to diffuse through the crystalline barrier. As expected, the activation energy for crystallization decreases with progressing crystallization $\left(1.3 \mathrm{eV}\right.$ between 220 and $250{ }^{\circ} \mathrm{C}$ and $\approx 0.7 \mathrm{eV}$ between 260 and $300{ }^{\circ} \mathrm{C}$ ). All these observations are in good agreement with results observed for amorphous and crystalline multilayered films. [21,41]

Table 2: The activation energy for interdiffusion and crystallization of Cr-rich thin multilayered films of different composition and repeating unit thickness.

\begin{tabular}{|c|c|c|c|c|}
\hline sample & $\begin{array}{l}\text { Cr content } \\
\text { /at- } \%\end{array}$ & $\begin{array}{c}\text { repeating unit } \\
\qquad / \AA\end{array}$ & $\begin{array}{c}\text { activation energy and } \\
\text { temperature range } \\
/ \mathrm{eV} \text { and }{ }^{\circ} \mathrm{C}\end{array}$ & $\begin{array}{c}\text { type of } \\
\text { experiment }\end{array}$ \\
\hline MR33_1 & $61(5)$ & $10.3(5)$ & $\begin{array}{c}0.77(3) / 50 \text { to } 72 \\
1.32(9) / 142 \text { to } 166\end{array}$ & in-situ XRR \\
\hline MR34_1 & $60(5)$ & $10.8(5)$ & $\begin{array}{l}3.42(6) / 138 \text { to } 146 \\
0.81(2) / 148 \text { to } 156\end{array}$ & in-situ XRD \\
\hline MR111_2 & $72(5)$ & $10.5(5)$ & $\begin{array}{l}0.10(1) / 150 \text { to } 200 \\
0.62(3) / 238 \text { to } 300\end{array}$ & in-situ XRR \\
\hline MR111_4 & $72(5)$ & $10.9(5)$ & $\begin{array}{l}0.28(5) / 160 \text { to } 210 \\
0.19(2) / 230 \text { to } 300\end{array}$ & in-situ XRD \\
\hline MR36_4 & $70(5)$ & $15.7(5)$ & $\begin{array}{c}0.09(1) / 100 \text { to } 200 \\
1.29(14) / 250 \text { to } 300 \\
1.32(12) / 220 \text { to } 250 \\
0.74(3) / 260 \text { to } 300\end{array}$ & in-situ XRR \\
\hline
\end{tabular}

A different result was obtained for a sample with a repeating unit of $16.7 \AA$ but containing less $\mathrm{Cr}$ in the as-deposited film (MR76_2, Table 1). The multilayered film with 59 at-\% $\mathrm{Cr}$ is amorphous in the as-deposited state and starts to crystallize to form hexagonal $\mathrm{CrSb}$ at $140{ }^{\circ} \mathrm{C}$ without any significant change of the lattice parameters up to $300{ }^{\circ} \mathrm{C}$. However, the presence of a $1^{\text {st }}$ order Bragg maximum up to $300{ }^{\circ} \mathrm{C}$ in the XRR pattern indicates that both, the crystalline and the amorphous phase coexist (see Figure 2, inset). Further heating leads to the formation of the phase $\mathrm{CrSb}_{2}$ at $420{ }^{\circ} \mathrm{C}$. The diffraction pattern shows that the two binary compounds $\mathrm{CrSb}$ and $\mathrm{CrSb}_{2}$ as well as elemental $\mathrm{Sb}$ and $\mathrm{Cr}$ are present at $550{ }^{\circ} \mathrm{C}$ (see Figure $\mathrm{S} 2)$. Therefore, it can be assumed that elemental $\mathrm{Sb}$ reacts with crystalline $\mathrm{CrSb}$ at the $\mathrm{CrSb}$ $\mathrm{Sb}$ interface and forms orthorhombic $\mathrm{CrSb}_{2}$ (space group: Pnnm). 
A more detailed insight into the solid state reactivity of the Cr-rich multilayered films (MR36_3, 72 at-\% Cr) with a thicker repeating unit is obtained performing an isothermal insitu XRD measurement. The sample was heated stepwise $\left(2{ }^{\circ} \mathrm{C} / \mathrm{step}\right)$ until the $\mathrm{Cr}$-rich phase has formed which occurred at $262{ }^{\circ} \mathrm{C}$. Afterwards the film was annealed at this temperature for $72 \mathrm{~h}$ and XRD patterns were taken every $2 \mathrm{~h}$. The integrated intensities of the (101) reflection was used to perform a Sharp-Hancock analysis [42] (Figure 5). The data show two regions where the slope $\left(\mathrm{m}_{\mathrm{x}}\right)$ is significantly different. At the beginning of the in-situ experiment, the reaction can be described as nucleation controlled due to the low value $\mathrm{m}_{1}$ of 0.32(6). After annealing for $20 \mathrm{~h}$ a change in the reaction mechanism is indicated as the slope increases to $\mathrm{m}_{2}=2.00(7)$, where the reaction progress obeys a diffusion controlled process. [42-45]



Figure 5: Sharp-Hancock plot of the intensities of the (101)-reflection of a sample (MR36_3) with a repeating unit of $14.0 \AA$ and a Cr content of 72 at-\%.

As shown above, on heating the multilayered film only a partial interdiffusion is observed, which means that amorphous $\mathrm{Cr}$-Sb layers are located in-between the single elemental layers. Nucleation and crystallization starts in the amorphous interlayer leading to a diffusion barrier when the compound crystallizes. After a certain reaction progress the crystal growth can only be achieved by diffusion of $\mathrm{Cr}$ and $\mathrm{Sb}$ through the crystalline phase. In a third step decomposition of the Cr-rich phase and growth of stoichiometric $\mathrm{CrSb}$ is accompanied by formation of nanocrystalline $\mathrm{Cr}$. Therefore the overall reaction for multilayered films with a repeating unit below the "critical thickness" of about $10 \AA$ might be described by the following scheme, were "a" means amorphous and "m" stands for multilayer (1). 
$\mathrm{a}-(\mathrm{Cr} / \mathrm{Sb})_{\mathrm{m}} \stackrel{\stackrel{<250{ }^{\circ} \mathrm{C}}{\longrightarrow} \mathrm{a}-(\mathrm{Cr} / \mathrm{CrSb} / \mathrm{Sb} / \mathrm{CrSb})_{\mathrm{m}}}{\stackrel{250-300{ }^{\circ} \mathrm{C}}{\longrightarrow} \text { hex. } \mathrm{Cr}_{1+x} \mathrm{Sb}+\mathrm{a}-\mathrm{Cr} \stackrel{<400-450{ }^{\circ} \mathrm{C}}{\longrightarrow} \text { hex. } \mathrm{CrSb}+\mathrm{a}-\mathrm{Cr}}$

Diffraction patterns of the annealed samples were compared with respect to the $\mathrm{Cr}$ content of the film samples determined by EDX analysis in the as-deposited state (see Figure 6). The XRD pattern shows a significant shift of the (102) and (110) reflections of the hexagonal phase with increasing $\mathrm{Cr}$ content to higher and lower angles, respectively. This phenomenon is caused by an expansion of the lattice parameter $a$ and a contraction of $c$ (Table 3 and Figure S3). According to Rietveld refinements the best fits were achieved when the atomic position $(1 / 3,1 / 3,3 / 4)$ was occupied with $\mathrm{Cr}$ and the occupancy was set as free varying parameter during refinement (Table S1) yielding the composition $\mathrm{Cr}_{1.6} \mathrm{Sb}$ for sample MR36_3 with 72 at-\% Cr. It must be mentioned that the annealed samples do not change significantly in composition compared to the as-deposited state. According to these results it is assumed that the residual $\mathrm{Cr}$ in the film is still amorphous up to $300{ }^{\circ} \mathrm{C}$. Furthermore, the coherently scattering domain size was extracted from the refinements and is found to decrease with increasing $\mathrm{Cr}$ content. Among the samples with 72 at- $\% \mathrm{Cr}$ the unit cell volume increases with increasing domain size. As it was shown, the Cr-rich samples only interdiffused partially, crystal growth might be limited by the relatively short distance of the $\mathrm{Cr}-\mathrm{Cr} / \mathrm{Sb}$ and $\mathrm{Sb}-\mathrm{Cr} / \mathrm{Sb}$ interfaces where deficiency of one of the constituents exists.

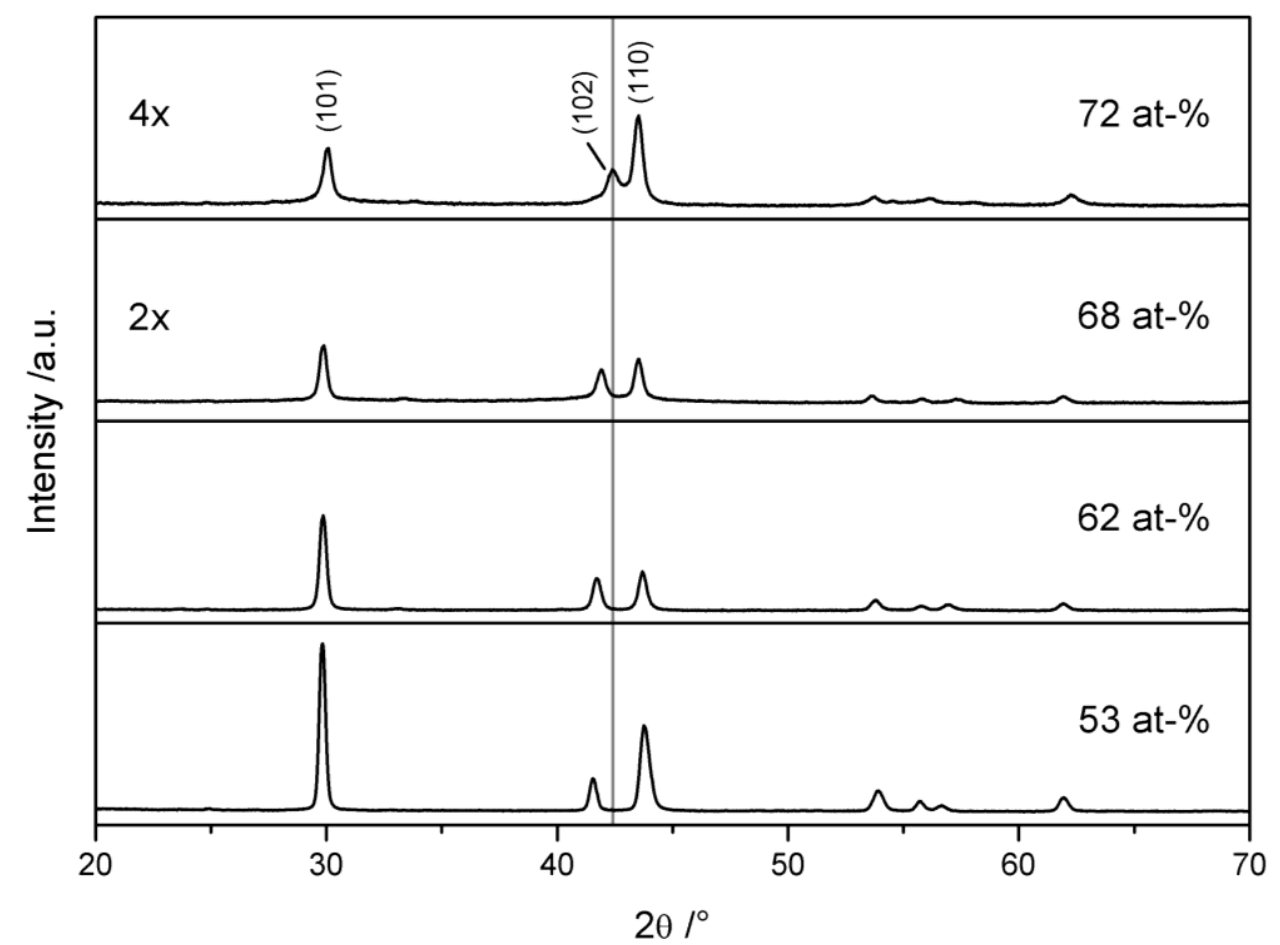

Figure 6: Ex-situ X-ray diffraction pattern of films with different $\mathrm{Cr}$ content show a shift of the position of the reflections. MR33_2: 53 at-\% Cr (bottom), MR34_3: 62 at-\% $\mathrm{Cr}\left(2^{\text {nd }}\right.$ from bottom), MR35_4: 68 at-\% Cr $\left(2^{\text {nd }}\right.$ from top) and MR36_3: 73 at-\% Cr (top). The grey line is only a guide for the eye. Please note: the intensity in the top two patterns was enlarged by $4 \mathrm{x}$ and $2 \mathrm{x}$, respectively, for better visualization. 
Table 3: Details of the annealed films together with parameters extracted from Rietveld-refinements: crystallite size, lattice parameter and occupancy factor of the atom position $(1 / 3,1 / 3,3 / 4)$. These results are graphically represented in Figure S3.

\begin{tabular}{ccccccc}
\hline sample & $\begin{array}{c}\text { Cr content } \\
\text { /at-\% }\end{array}$ & $\begin{array}{c}\text { repeating } \\
\text { unit } / \AA\end{array}$ & $\begin{array}{c}\text { crystallite } \\
\text { size } / \mathrm{nm}\end{array}$ & $\begin{array}{c}\text { lattice parameter } \\
\text { a and c } / \AA\end{array}$ & $\begin{array}{c}\text { Cr occ. } \\
(1 / 3,1 / 3,3 / 4)\end{array}$ & comment \\
\hline MR33_2[21] & $53(5)$ & $11.4(5)$ & $53(2)$ & $\begin{array}{c}4.1356(2) / \\
5.4700(4)\end{array}$ & 0 & ex-situ $300{ }^{\circ} \mathrm{C}$ \\
& & & & $\begin{array}{c}4.1466(2) / \\
5.4365(3)\end{array}$ & 0.1 & ex-situ $300{ }^{\circ} \mathrm{C}$ \\
MR34_3 & $62(5)$ & $11.2(5)$ & $43(1)$ & $\begin{array}{c}4.1651(3) / \\
5.3928(6)\end{array}$ & 0.4 & ex-situ $300{ }^{\circ} \mathrm{C}$ \\
MR35_4 & $68(5)$ & $15.4(5)$ & $35(2)$ & $\begin{array}{c}4.1691(6) / \\
5.2999(11)\end{array}$ & 0.6 & ex-situ $262{ }^{\circ} \mathrm{C}$ \\
MR36_3 & $72(5)$ & $14.0(5)$ & $15(1)$ & $\begin{array}{c}4.1696(5) / \\
5.3425(9)\end{array}$ & 0.5 & ex-situ $300{ }^{\circ} \mathrm{C}$ \\
MR111_2 & $72(5)$ & $11.1(5)$ & $29(2)$ & $\begin{array}{c}4.1643(6) / \\
5.3118(1)\end{array}$ & 0.5 & ex-situ $300{ }^{\circ} \mathrm{C}$ \\
MR118_2 & $72(5)$ & $18.0(5)$ & $16(1)$ & & &
\end{tabular}

\subsection{Thermodynamic stability}

The existence of such a Cr-rich phase with composition $\mathrm{Cr}_{1.6} \mathrm{Sb}$ is surprising, because only $\mathrm{CrSb}$ and $\mathrm{CrSb}_{2}$ are known from the equilibrium phase diagram. The thermodynamic stability of this phase was investigated by differential scanning calorimetry. A film with a total thickness of about $1300 \mathrm{~nm}$ was deposited on PMMA consisting of 73 at-\% $\mathrm{Cr}$ and 885 repeating units with a double-layer thickness of about $15 \AA$ A. In the as-deposited state the XRD pattern demonstrate the amorphous state. At lower temperatures a weak modulation is observed in the DSC curve which is assigned to interdiffusion or nucleation (Figure 7). On further heating, a continuous increase of the base line is observed that might be traced back to the very low amount of sample used in the experiment. On further heating no exothermic signal is observed indicating a crystallization of the new Cr-rich compound. However, the insitu XRD experiments crystallization occurred over a large temperature range $\left(220{ }^{\circ} \mathrm{C}\right.$ to 300 ${ }^{\circ} \mathrm{C}$ ) and therefore, it is not surprising that no change in heat-flow can be detected. A pronounced exothermal event is seen at $467{ }^{\circ} \mathrm{C}$ which perfectly corresponds to the temperature observed in XRD measurements for the decomposition of $\mathrm{Cr}_{1.6} \mathrm{Sb}$ into thermodynamically stable $\mathrm{CrSb}$ and elemental $\mathrm{Cr}$. These observations indicate that $\mathrm{Cr}_{1.6} \mathrm{Sb}$ is metastable and is formed by kinetic control. 


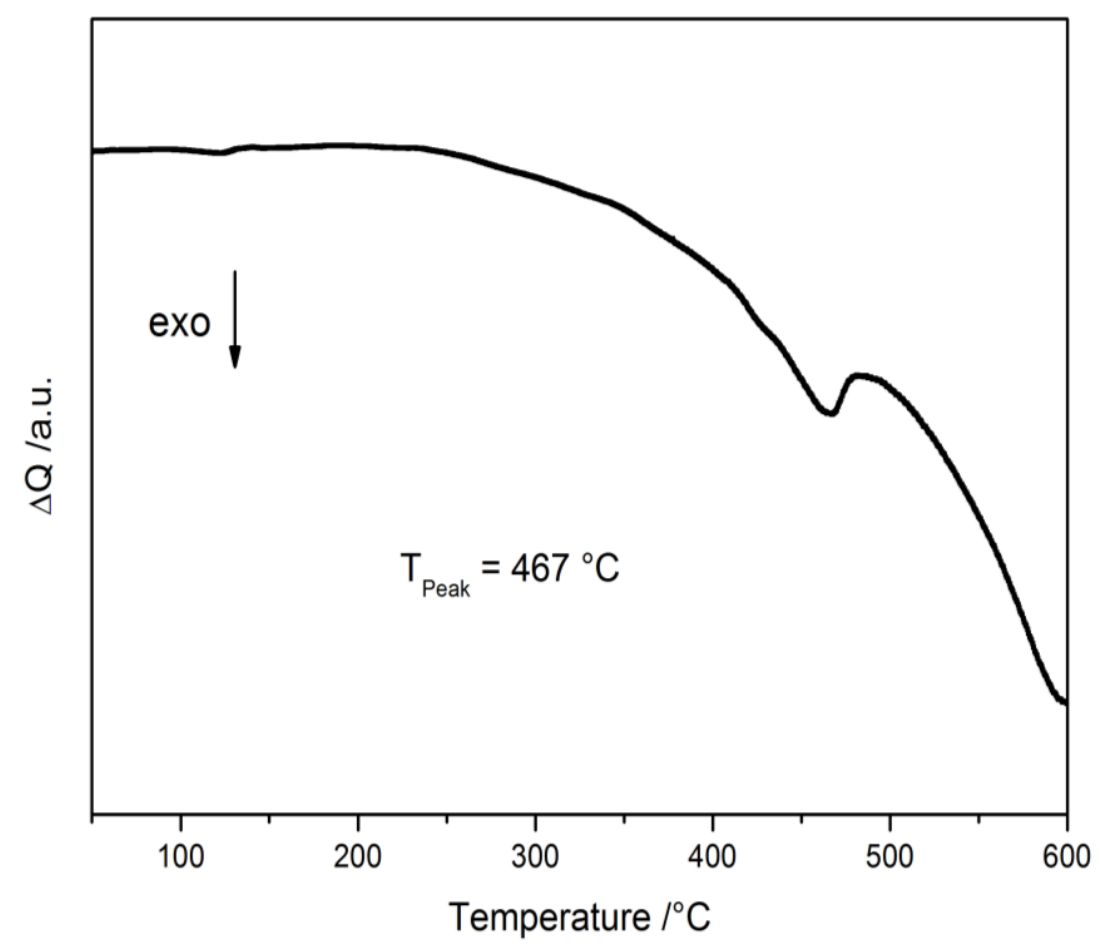

Figure 7: Differential scanning calorimetry data for a multilayered film (MR65_2) with a repeating unit of $15.4 \AA$ and a $\mathrm{Cr}$ content of $\sim 73$ at-\%. A heating rate of $5 \mathrm{~K} / \mathrm{min}$ was applied during the scan. The exothermal event at $467{ }^{\circ} \mathrm{C}$ corresponds to the transition observed in the in-situ XRD measurements.

\subsection{Topology}

The surface topology of the film samples was investigated in the as-deposited state as well as after annealing using AFM in contact mode and SEM. The sample MR36_1 (Table 1) shows a very low root mean square surface roughness of $\mathrm{R}_{\mathrm{rms}}=2.8(5) \AA$ after deposition (Figure 8: left), which is close to the surface roughness of the blank Si substrate (2.1 $\AA$ ). After annealing at $\mathrm{T}=300{ }^{\circ} \mathrm{C}$, the roughness increased slightly to $8(2) \AA$ caused by nucleation and growth of nanocrystalline $\mathrm{Cr}_{1+x} \mathrm{Sb}$ and additional, amorphous $\mathrm{Cr}$. An AFM scan as well as a SEM image show randomly distributed spots in sub-micron scale (Figure 8: middle, Figure S4, left). An EDX line scan was performed on the annealed sample (MR28_1, Table 1) and shows a constant $\mathrm{Cr}: \mathrm{Sb}$ ratio over a distance of $3.3 \mu \mathrm{m}$ (Figure S4, right), which is about 100 times longer than the determined size of the coherently scattering domains. Consequently, no separated $\mathrm{Cr}$ was observed in the EDX scan. This observation might also arise from averaging over the total film thickness as the electron beam is penetrating the film completely. After heating at $\mathrm{T}=550{ }^{\circ} \mathrm{C}$ (MR36_1, Table 1) a roughness of 80(5) $\AA$ was calculated from the AFM scan (Figure 8, right). The increase in surface roughness is most likely caused by the formation of larger crystallites in the decomposed sample. 

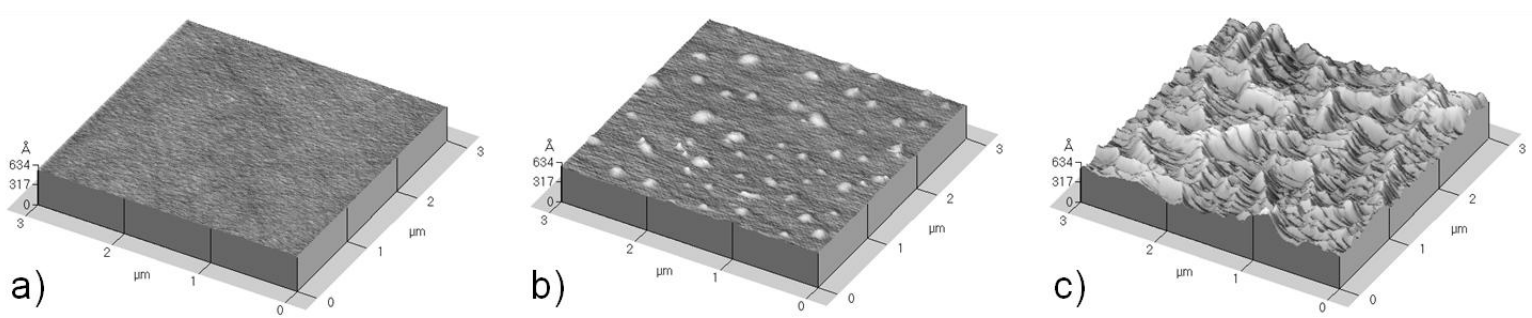

Figure 8: AFM images of a sample possessing a $\mathrm{Cr}$ content of 72 at-\% in the as-deposited state (a), after heating to $300{ }^{\circ} \mathrm{C}$ (b) and after $550{ }^{\circ} \mathrm{C}$ (c). Please note that at $300{ }^{\circ} \mathrm{C} \mathrm{Cr}_{1+x} \mathrm{Sb}$ has formed, whereas at $550{ }^{\circ} \mathrm{C}$ decomposition into $\mathrm{CrSb}$ and elemental $\mathrm{Cr}$ took place.

\subsection{Transmission electron microscopy}

A more detailed microstructure investigation was carried out in order to determine the local composition of the film and to verify the crystal structure and lattice parameters of these crystalline regions. Therefore two lamellae were cut out of the Cr-rich sample MR118_2 (Table 1) using the FIB techniques. To reduce interferences of different crystalline grains on top of each other the thickness of the lamella was thinned down to $\sim 15-20 \mathrm{~nm}$ corresponding to the average coherently scattering domain size (Figure S5).

Electron diffraction patterns of regions Pos5 and Pos6 (compare Figure S5) reveals the polycrystalline nature of the sample (Figure 9). The diffraction rings are indicated by white lines (1-6). The respective d-values match well with the results from the XRD refinement. An EDX analysis of this section (Pos5 and Pos6, see Figure S5) gives an average $\mathrm{Cr}$ content of 58(3) at-\% indicating a $\mathrm{Cr}$-rich hexagonal phase $\mathrm{Cr}_{1.4} \mathrm{Sb}$. A lattice parameter $a=4.186(35) \AA$ was calculated from further diffraction data on the second lamella showing the zone axis [001]. Within these errors, the lattice parameter $a$ agrees very well with the value obtained from Rietveld refinements (see Table 3).

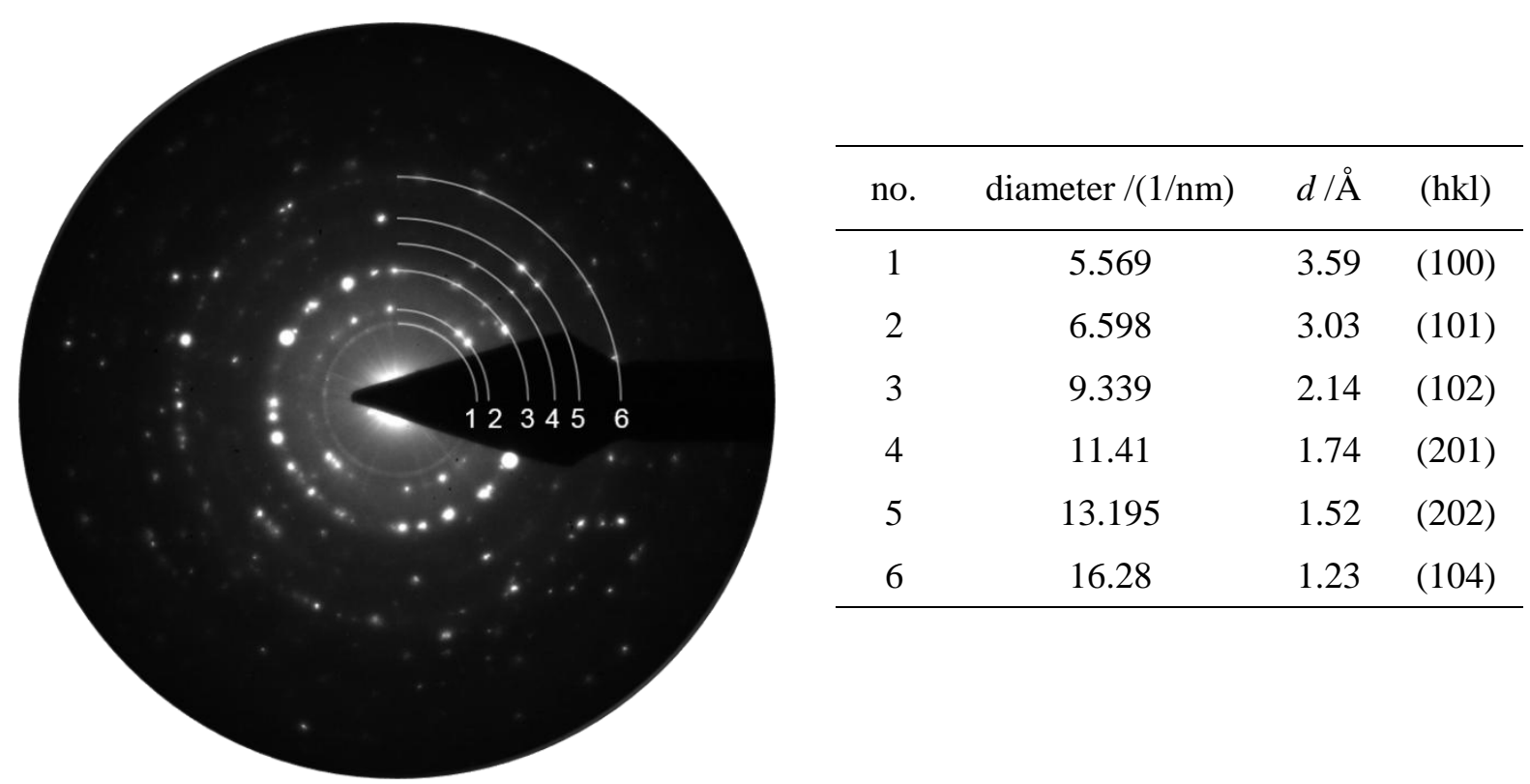

Figure 9: Electron diffraction pattern recorded from position Pos5 and Pos6 (compare Figure S5). The diffraction rings are indicated by line 1 to 6 and listed together with the corresponding d-values and (hkl)-indices. 
The crystalline regions and their compositions were investigated using a combination of HRTEM, FFT and STEM with EDX on Pos1 (Figure S5). Areas with different crystallinity are observed in HRTEM images (Figure 10a). Completely crystalline regions are surrounded by a matrix where amorphous parts and only faint lattice fringes are visible. From the region with high crystallinity (cf. marked with red square in Figure 10a), a FFT (see Figure 10a, inset) is received showing the zone axis [010] of hexagonal $\mathrm{Cr}_{1.4} \mathrm{Sb}\left(\mathrm{Ni}_{2} \mathrm{In}\right.$-type), which also correlates to the d-values of the XRD data.

In STEM mode, an EDX analysis of this area indicates a Cr-rich crystalline phase with a $\mathrm{Cr}$ content up to 63 at- $\%$ measured at point 1 , whereas only 53 at- $\%$ are recorded at point 2 . The EDX analysis in TEM confirms the total Cr content in the film determined in SEM. However, the local $\mathrm{Cr}$ amount varies significantly between 45 at-\% and 72 at-\% (compare tables in Figure S5).

The image gathered from the second lamella using HAADF mode (Figure 10c) clearly shows a difference in the Z-contrast indicating the local difference in composition of the film. Please note: During this TEM investigation a few reflections were observed in ED patterns which are considered to origin from elemental $\mathrm{Sb}$ as they do not match with the crystalline $\mathrm{Cr}_{1+x} \mathrm{Sb}$ phase. This leads to the conclusion that nanocrystalline precipitations of $\mathrm{Sb}$ coexist with the new Cr-rich phase in an amorphous Cr matrix.
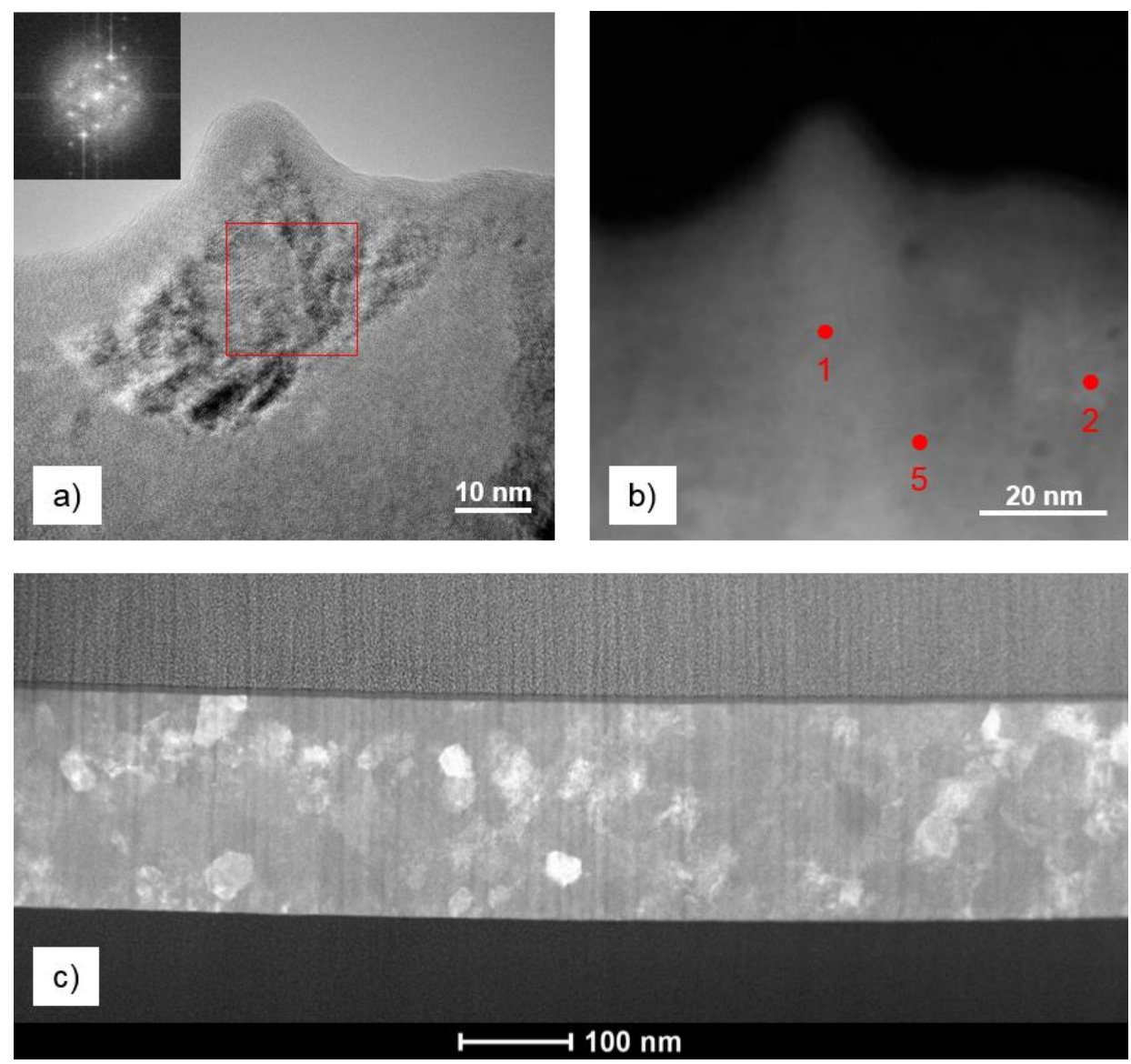

Figure 10: a) HRTEM micrograph of a crystalline section. Inset: The FFT pattern shows the zone axis [010] obtained from the area marked with a red square. b) STEM image of the same section. Point 1, 2 and 5 were used for EDX-analysis (see Figure S5). c) Overview of a second lamella of the $\mathrm{Cr}_{1.5} \mathrm{Sb}$ sample (MR118_2) in HAADF mode. 


\subsection{Specific resistivity and Seebeck Coefficient}

The electrical characterization of Cr-rich samples was carried out in a temperature range between $2 \mathrm{~K}$ and $310 \mathrm{~K}$ for a sample in the as-deposited state as well as for annealed samples described in the previous sections. The specific resistivity $\rho$ of a multilayered film in the asdeposited state (MR119_1, 72 at-\% Cr) and annealed samples (MR111_2 and MR118_2, 72 at-\% Cr) with the $\mathrm{Cr}$-rich hexagonal phase $\mathrm{Cr}_{1.5} \mathrm{Sb}$ are plotted in Figure 11 (see Table 1). The data of the cooling $(310 \mathrm{~K}$ to $2 \mathrm{~K})$ and the heating cycles $(2 \mathrm{~K}$ to $310 \mathrm{~K})$ do not differ significantly. All samples show a semi-metallic behavior with a very small slope resulting in very low activation energies. The lowest value for $\rho$ was found for the amorphous sample (MR119_1, black), whereas the highest value was observed for the sample with a thicker repeating unit (MR118_2, blue).

The differences of the resistivity among the annealed samples might be due to different coherent scattering domain sizes (see also section 3.1 X-ray reflectivity and X-ray diffraction). A smaller domain size results in a larger number of crystalline grains and consequently in a larger number of grain boundaries leading to a higher resistivity compared to crystalline regions. Hence, smaller crystalline domains (16(1) $\mathrm{nm}$ ) as observed for the film with a thicker repeating unit (MR118_2, $18 \AA$ ) display a larger resistivity. Annealing the Crrich film up to $550{ }^{\circ} \mathrm{C}$, where the $\mathrm{Cr}$-rich phase decomposes into $\mathrm{CrSb}$ and crystalline $\mathrm{Cr}$, the specific resistivity changes into metallic behavior as can be expected from thermodynamic stable $\mathrm{CrSb}$ and metallic $\mathrm{Cr}$ (see Figure S6) [21,46].

Applying the Arrhenius equation ( $2, E_{A}=$ activation energy, $k_{B}=$ Boltzmann constant; $T=$ temperature), the calculated activation energies are lower than $0.01 \mathrm{eV}$ for all samples (see Figure 2).

$\ln \left(\rho / \rho_{0}\right)=E_{A} /\left(k_{B} T\right)$

In addition to resistivity measurements, sample MR111_2 (72 at-\% Cr) consisting of $\mathrm{Cr}_{1.5} \mathrm{Sb}$ was also used to determine the Hall coefficient. The temperature dependent measurement was carried out between $2 \mathrm{~K}$ and $310 \mathrm{~K}$ applying an electrical current of $100 \mu \mathrm{A}$. A negative Hall coefficient $\mathrm{R}_{\mathrm{H}=0,2 \mathrm{~T}} \approx-3 \times 10^{-2} \mathrm{~cm}^{3} / \mathrm{C}$ was observed for the whole temperature range indicating that electron are the major charge carriers. In general, this value is very low compared to e.g. $\mathrm{InSb}\left(\mathrm{R}_{\mathrm{H}=3080 \mathrm{G}} \approx-3.5 \times 10^{2} \mathrm{~cm}^{3} / \mathrm{C}\right)$ used as Hall sensor. [47] 


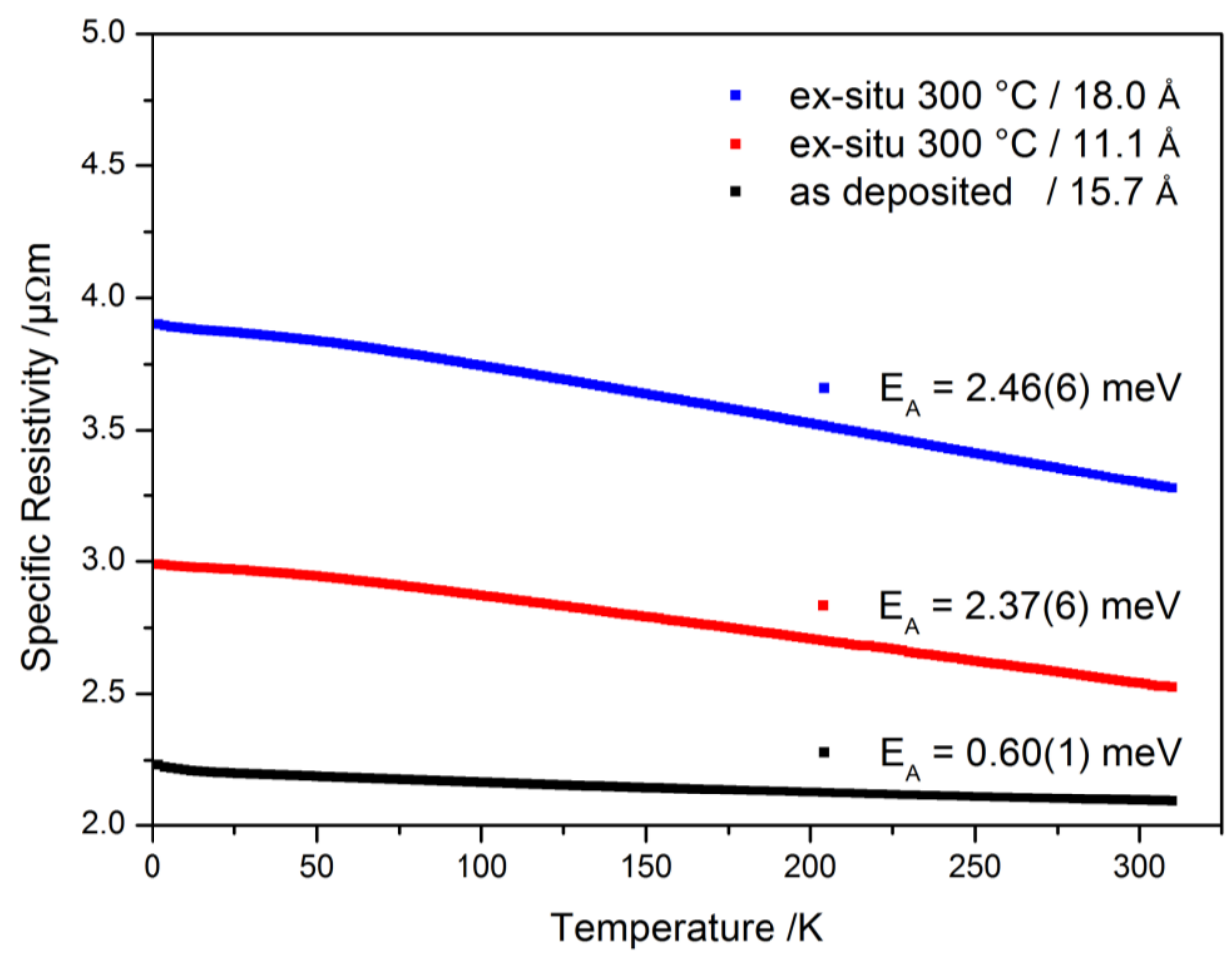

Figure 11: Temperature-dependent specific resistivity of samples with 72 at- $\% \mathrm{Cr}$ measured from $2 \mathrm{~K}$ to $310 \mathrm{~K}$ : MR119_1 (black), MR111_2 (red) and MR118_2 (blue). The activation energies are calculated for a temperature range between $140 \mathrm{~K}$ and $310 \mathrm{~K}$.

After the electrical measurement of the amorphous sample the film MR119_1 with 72 at-\% Cr and a repeating unit of $15.7 \AA$ was cut into bars of $10 \times 2 \mathrm{~mm}$ in order to carry out temperature dependent resistivity and Seebeck coefficient measurements at elevated temperatures in a range from room temperature to $570{ }^{\circ} \mathrm{C}$ (see Figure S7). The temperature dependent specific resistivity is very low, $\rho \sim 1.3 \mu \Omega \mathrm{m}$, and does not change significantly as long as the sample stays amorphous at temperatures below $\sim 300{ }^{\circ} \mathrm{C}$. On further heating a slightly increase of the resistivity is recorded, $\rho \approx 1.45 \mu \Omega \mathrm{m}$ originating from the transition of the amorphous state into the crystalline $\mathrm{Cr}$-rich phase. Annealing up to $\mathrm{T}=570{ }^{\circ} \mathrm{C}$ leads to the decomposition of the $\mathrm{Cr}$-rich phase into $\mathrm{CrSb}+\mathrm{Cr}$ causing a larger resistivity of the sample. This observation agrees with resistivity measurements of annealed films at $262{ }^{\circ} \mathrm{C}$ (MR36_3) and $550{ }^{\circ} \mathrm{C}$ (MR36_1), compare Figure S6. However, the measured values for the specific resistivity at room temperature are lower compared to those reported for stoichiometric $\mathrm{CrSb}(\rho \approx 4.5$ $\mu \Omega \mathrm{m})$. [21,46,48]

The Seebeck coefficient is slightly negative for the amorphous multilayered film MR119_1 at low temperatures (see Figure S7). An increase of the absolute value of the Seebeck coefficient to $\mathrm{S} \sim-25 \mu \mathrm{V} / \mathrm{K}$ becomes evident when the sample crystallized and a slight increase of $\mathrm{S}$ is observed as the sample is further annealed. The values for $S$ for the nano-structured Cr-rich antimonide $\mathrm{Cr}_{1.5} \mathrm{Sb}$ seem to be very small compared to typical thermoelectric materials [49]. Although, the negative values for $S$ indicate that electrons are charge carriers in this metastable phase. 


\subsection{Electronic Structure Calculations}

As discussed above, non-stoichiometric $\mathrm{Cr}_{1.6} \mathrm{Sb}$ phase having a $\mathrm{Ni}_{2} \mathrm{In}$-based structure (which can be also interpreted as NiAs-structure with partial occupation of the interstitial sites), has been synthesized experimentally. Accordingly, the DFT calculations have been performed for this compound in order to investigate the properties governed by the electronic structure. As a first step, a geometry optimization has been performed to find out the equilibrium structure parameters for the metastable system with $\mathrm{Ni}_{2} \mathrm{In}$-based structure. In the case of $\mathrm{CrSb}$ having NiAs-structure the structure parameters are known from the experiment [50] and were discussed on the basis of total energy calculations in our previous work. [51] Figure 12 a) displays the total energy as a function of lattice parameter for the ferromagnetic (FM) and non-magnetic (NM) states for stoichiometric $\mathrm{Cr}_{2} \mathrm{Sb}$ with $\mathrm{Ni}_{2} \mathrm{In}$-structure, demonstrating a more stable ferromagnetic (FM) state for this compound. Note that these results are calculated for the optimized c/a ratio, i.e. c/a $=1.25$. In addition, in the case of the non-stoichiometric $\mathrm{Cr}_{1.6} \mathrm{Sb}$ alloy the preferable distribution of $\mathrm{Cr}$ atoms has been also investigated. Two types of structures have been considered: (i) with uniform distribution of $\mathrm{Cr}$ atoms over the interstitial positions in the NiAs-structure and (ii) a layered structure with alternating fully occupied and partially occupied interstitial Cr layers. The optimized c/a ratio for these systems is nearly the same, $\mathrm{c} / \mathrm{a}=1.265$, which is in very satisfying agreement with the experimental ratio $\mathrm{c} / \mathrm{a}=$ 1.273. The results of the total energy calculations for the FM and NM states are shown in Figure 12 (b). The calculations demonstrate that the FM state is more stable for both types of structures. The layered occupation of the interstitial positions by $\mathrm{Cr}$ atoms is more preferable when compared to the uniform $\mathrm{Cr}$ distribution, and results in a smaller lattice parameter $a$ both for the NM and for the FM states of the $\mathrm{Cr}_{1.6} \mathrm{Sb}$ alloy.



a)

Lattice parameter a / $\AA$

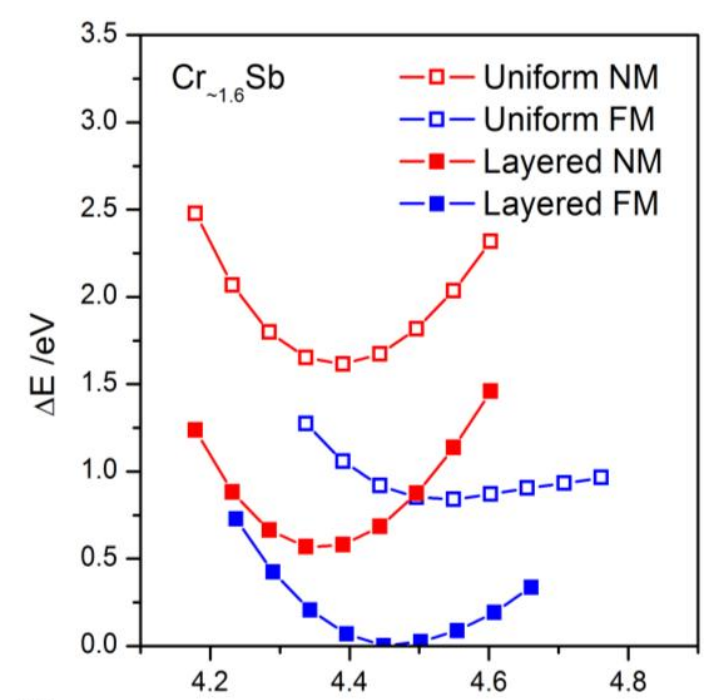

b) Lattice parameter a $/ \AA$

Figure 12: Total energy with respect to the minimum $\mathrm{E}_{\min }, \Delta \mathrm{E}=\mathrm{E}-\mathrm{E}_{\min }$, as a function of the lattice parameter $a$ for stoichiometric $\mathrm{Cr}_{2} \mathrm{Sb}$ with $\mathrm{Ni}_{2} \mathrm{In}$-structure with $c / a=1.25$ (a) and for $\mathrm{Cr}_{\sim 1.6} \mathrm{Sb}$ with $\mathrm{Ni}_{2} \mathrm{In}$-based structure (b), $c / a=1.265$. The blue lines and red lines correspond to the FM and NM states, respectively. The full symbols on the right panel represent the results for the system with alternating occupation of the interstitial positions by $\mathrm{Cr}$ atoms, while the open symbols correspond to the system with uniform $\mathrm{Cr}$ distribution over the interstitial positions. 


\subsection{Density of state}

The calculated densities of states (DOS) for the $\mathrm{FM}$ ordered $\mathrm{CrSb}$ and $\mathrm{Cr}_{2} \mathrm{Sb}$ are shown in Figure 13. These results demonstrate that both compounds, with NiAs- and $\mathrm{Ni}_{2} \mathrm{In}$-structures, show a clear metallic behavior with a finite DOS at the Fermi level for both spin channels. The $p$-states of $\mathrm{Sb}$ in $\mathrm{Cr}_{2} \mathrm{Sb}$ are moved down by the energy with respect to their position in $\mathrm{CrSb}$ (NiAs-structure) presumably due to stronger hybridization of the $\mathrm{Sb} p$-states with the $d$-states of surrounding $\mathrm{Cr}$ atoms. This leads also to the shift of the $\mathrm{Cr} d$-states up in energy. The DOS for the non-stoichiometric $\mathrm{Cr}_{1.6} \mathrm{Sb}$ alloys with two different distributions of the interstitial $\mathrm{Cr}$ atoms are compared in Figure 14 for the NM and FM states of the systems.
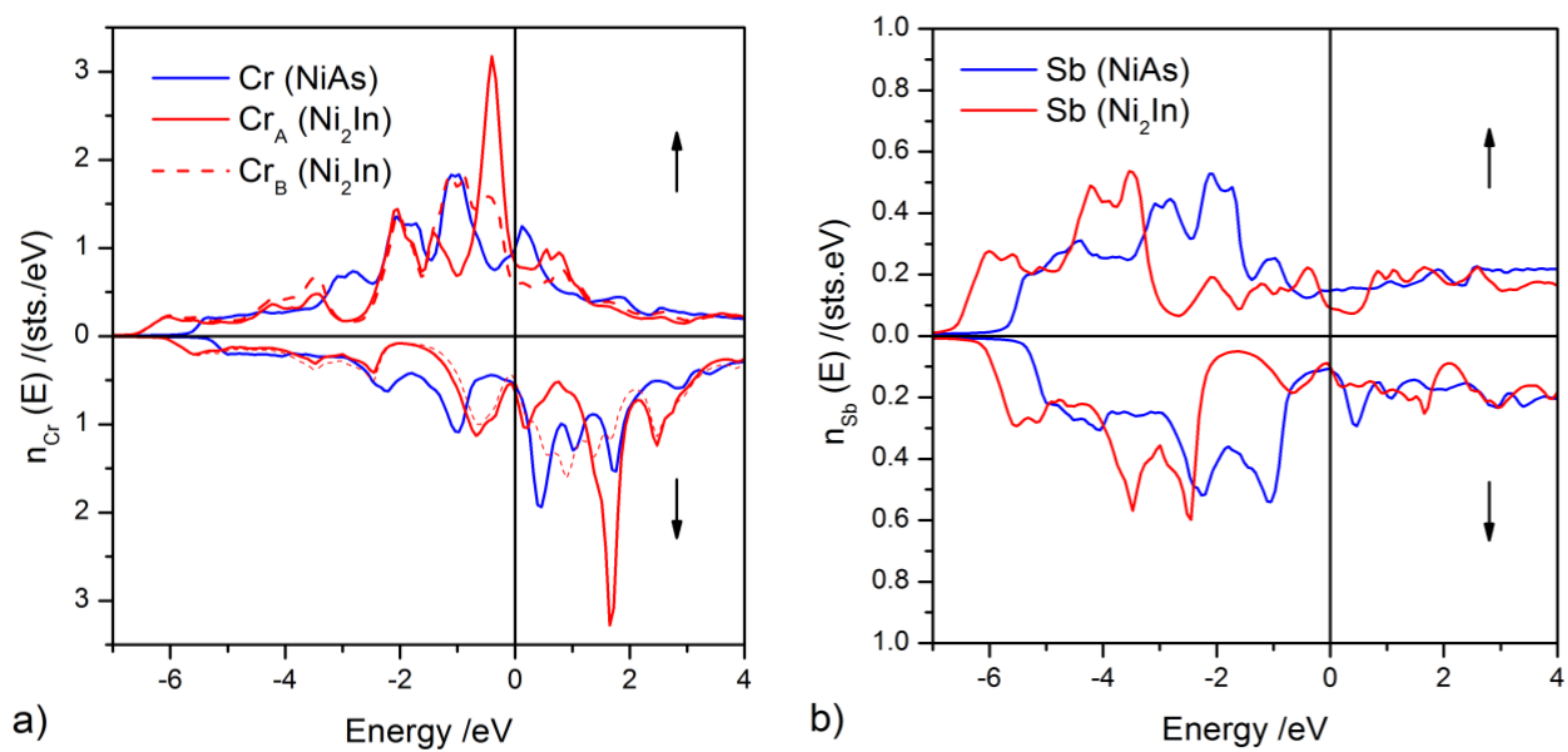

Figure 13: Spin-resolved density of states, $\mathrm{n}(\mathrm{E})$, on Cr sites (a) and on Sb sites (b), for FM CrSb (NiAs-structure, blue) and for $\mathrm{FM} \mathrm{Cr}_{2} \mathrm{Sb}\left(\mathrm{Ni}_{2} \mathrm{In}\right.$-structure, red).

Despite of a big difference in the total energy, corresponding to the states with different occupation of the interstitial positions (see Figure 12), their DOS do not have pronounced differences and demonstrate well defined metallic behavior. According to the discussion above, the transport measurements reveal a metallic-like behavior of the resistivity of $\mathrm{CrSb}+\mathrm{Cr}$ film (see Figure S6) in line with the present theoretical results. $\mathrm{The}^{\mathrm{Cr}} \mathrm{r}_{1.6} \mathrm{Sb}+\mathrm{a}-\mathrm{Cr}$ system, however, exhibits semiconductor-like properties at raising temperature. In general, this can be a property of both phases $\left(\mathrm{Cr}_{1.6} \mathrm{Sb}\right.$ and amorphous $\mathrm{Cr}$ matrix), but it can be also attributed either to amorphous $\mathrm{Cr}$ (a-Cr) or to the $\mathrm{Cr}_{1.6} \mathrm{Sb}$ alloy: taking into account finite resistivity at low temperature one of these phases can exhibit metallic behavior.

Here we will focus on the $\mathrm{Cr}-\mathrm{Sb}$ compounds, having a $\mathrm{Ni}_{2} \mathrm{In}$-based structure, and start with the discussions of the DOS for $\mathrm{Cr}_{2} \mathrm{Sb}$. Although the total energy calculations show that the FM (or even canted magnetic) state should be most preferable for this compound. 

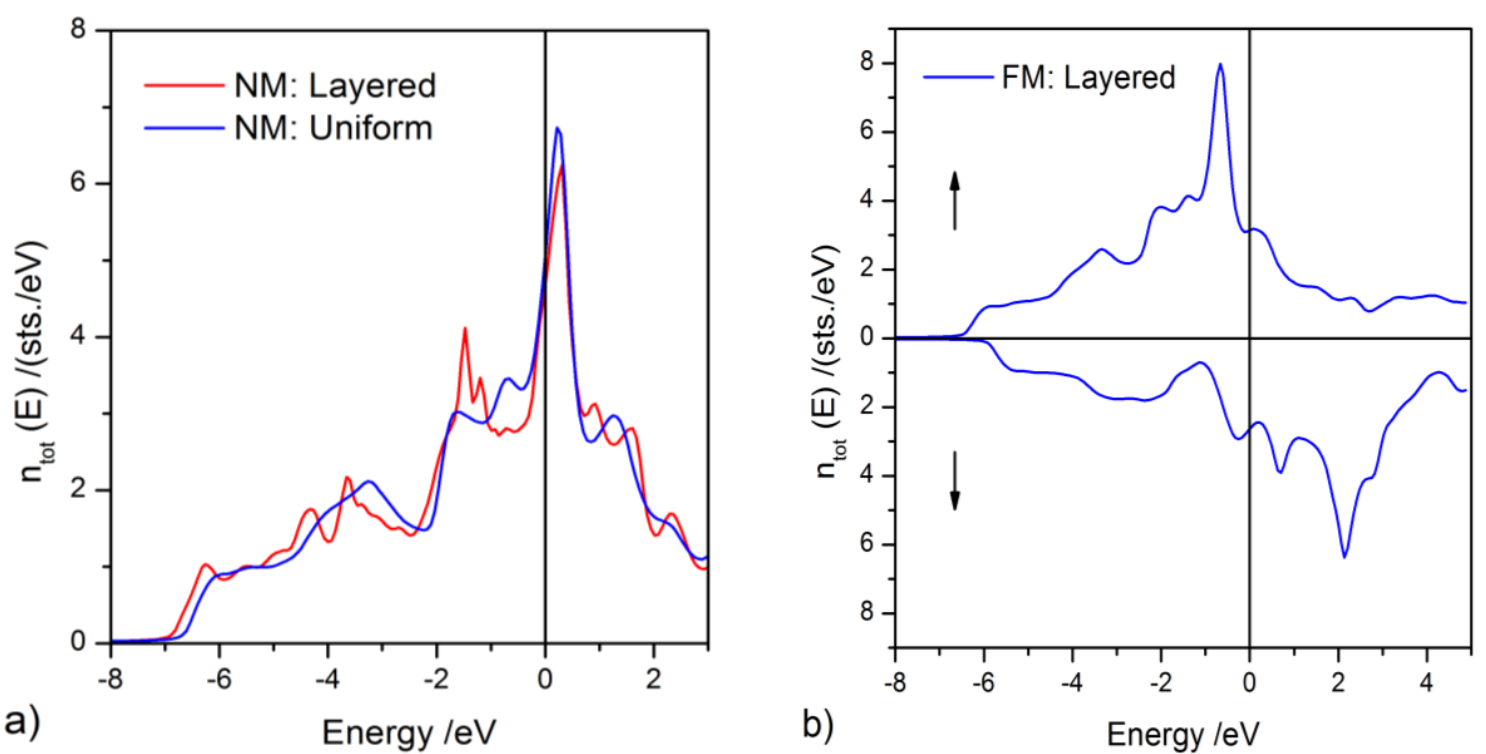

Figure 14: Total density of states, n(E), for the NM state (a) and for the FM state (b) of $\mathrm{Cr}_{\sim 1.6} \mathrm{Sb}$. Blue and red lines correspond to the uniform and layer-order $\mathrm{Cr}$ distributions, respectively.

The situation can be changed in the presence of structural distortions. As can be seen in Figure 15 (a), the DOS for the NM state has a maximum at the Fermi level indicating its instability. In general, two scenarios are possible to decrease the energy of the system: (i) to split the majority- and minority-spin states leading to a state with a spontaneous magnetic moment and metallic-like behavior, as discussed above; and (ii) to split the degenerated $\mathrm{Cr} d$ states in the vicinity of the Fermi level (see electron energy band structure in Figure 15 (b)), by introducing a structural distortion. The second scenario can lead to the NM state with an energy gap at the Fermi level and semiconductor-like behavior of the resistivity. This, however, needs more detailed investigations to find out the most probable structural distortion.

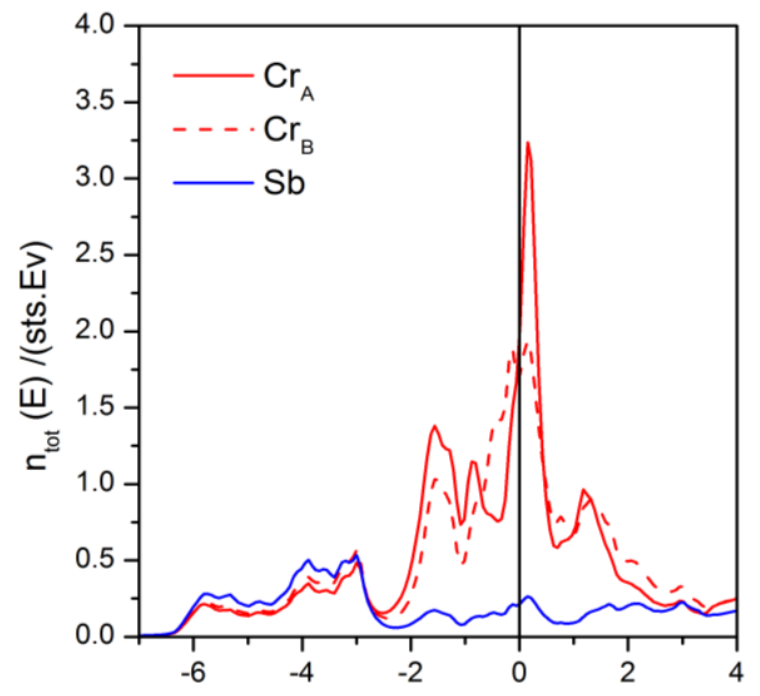

a)

Energy leV

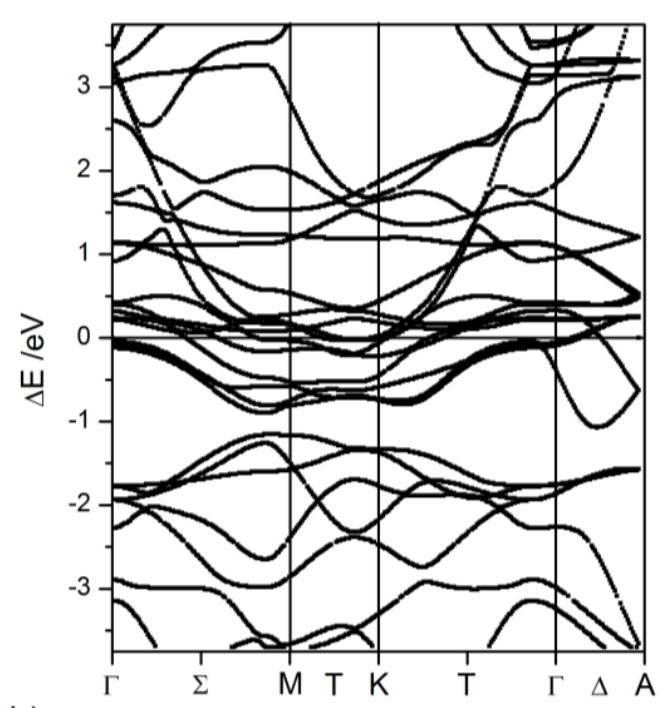

b)

Wave factor $/ \mathrm{k}$

Figure 15: Density of states, $\mathrm{n}(\mathrm{E})$, for the $\mathrm{NM} \mathrm{Cr}_{2} \mathrm{Sb}$ in the $\mathrm{Ni}_{2} \mathrm{In}$-structure (a): DOS on Cr sites are red and on $\mathrm{Sb}$ sites are blue. Electron energy band structure, $\mathrm{E}(\mathrm{k})$, for the $\mathrm{NM} \mathrm{Cr}_{2} \mathrm{Sb}(\mathrm{b})$. 
Similar arguments concern also the non-stoichiometric $\mathrm{NM} \mathrm{Cr}_{1.6} \mathrm{Sb}$ alloys (see DOS in Figure 14 (a)). Their Bloch spectral functions represented in Figure 16 (a) and (b) demonstrate narrow energy bands near the Fermi level, for which a splitting can be induced by a structural distortion. Note also that the uniform distribution of the interstitial $\mathrm{Cr}$ atoms results in an increase of disorder in the system leading to a smearing of the energy bands, as can be seen in Figure 16.


Figure 16: Bloch spectral function for the $\mathrm{NM} \mathrm{Cr}_{1.6} \mathrm{Sb}$ with layered order (a) and uniform (b) distribution of the interstitial $\mathrm{Cr}$ atoms, respectively. 


\subsection{Interatomic exchange interactions}

Although the total energy calculations for $\mathrm{Cr}_{1.6} \mathrm{Sb}$ and $\mathrm{Cr}_{2} \mathrm{Sb}$ have been performed only for the $\mathrm{NM}$ and FM states, showing more preferable stability for the latter one, their real magnetic structure can be more complicated, e.g., with antiferromagnetic (AF) or canted magnetic order. This can be seen from the results of calculations of the exchange coupling parameters represented in Figure 17. The $\mathrm{Cr}$ atoms in the interstitial positions $\left(\mathrm{Cr}_{\mathrm{B}}\right)$ couple ferromagnetically to each other, while the first neighbors in the NiAs-sublattice $\left(\mathrm{Cr}_{\mathrm{A}}\right)$ have rather strong AF interactions which should lead to the trend for the AF order within the NiAssublattice, similar to that observed for $\mathrm{CrSb}$ with NiAs-structure (compare Figure 1). However, the $\mathrm{AF}$ interactions between the $\mathrm{Cr}_{\mathrm{A}}$ and $\mathrm{Cr}_{\mathrm{B}}$ sub-lattices competing with the $\mathrm{AF}$ $\mathrm{Cr}_{\mathrm{A}}-\mathrm{Cr}_{\mathrm{A}}$ interactions can result in a non-collinear magnetic structure. Nevertheless, we do not expect an influence of magnetic order on the electronic structure in the system, which could be strong enough to lead to a transition from the metallic to the semiconducting state.

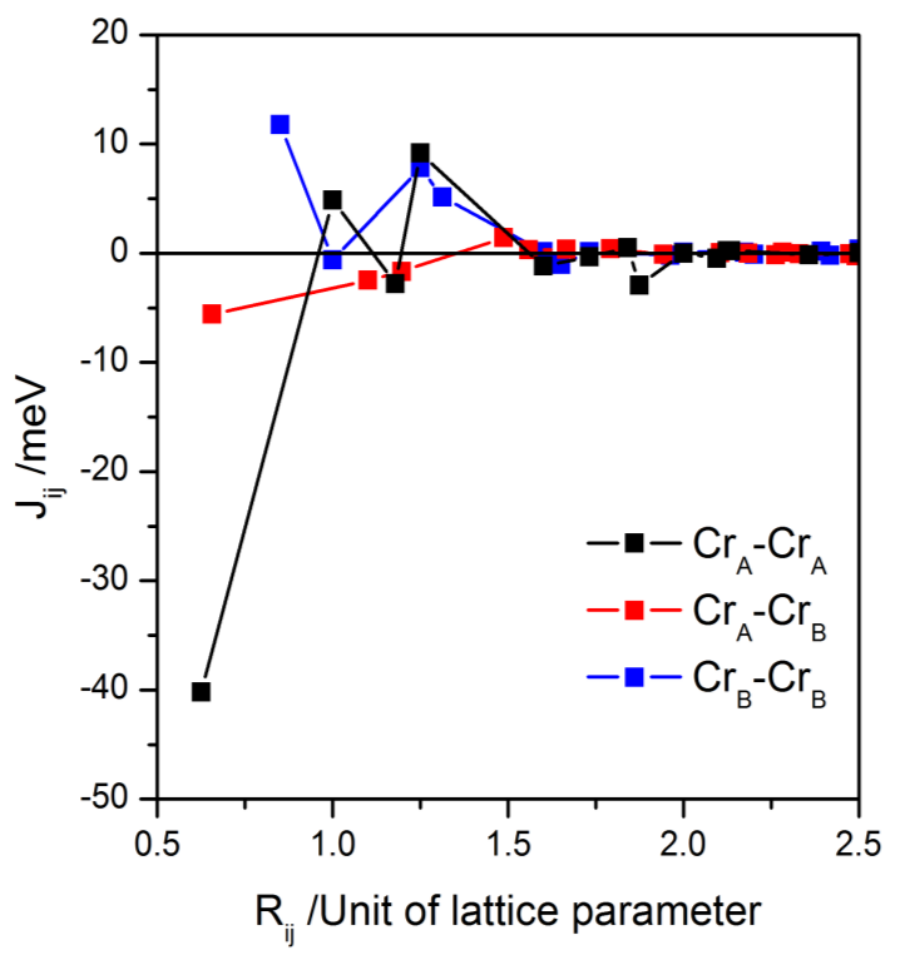

Figure 17: Cr-Cr exchange coupling parameters for $\mathrm{Cr}_{2} \mathrm{Sb}\left(\mathrm{Ni}_{2} \mathrm{In}\right.$-structure): $\mathrm{Cr}_{\mathrm{A}}-\mathrm{Cr}_{\mathrm{A}}$ (black), $\mathrm{Cr}_{\mathrm{A}}-\mathrm{Cr}_{\mathrm{B}}(\mathrm{red})$ and $\mathrm{Cr}_{\mathrm{B}}-\mathrm{Cr}_{\mathrm{B}}$ (blue). 


\section{Conclusion}

In summary, we presented the synthesis and characterization of interdiffusion and crystallization of a Cr-rich phase starting from amorphous multilayered films. The crystal structure of the new metastable compound corresponds to the $\mathrm{Ni}_{2} \mathrm{In}$-type structure, where the crystallographic position $(1 / 3,2 / 3,3 / 4)$ is partially occupied by additional $\mathrm{Cr}$. In films with larger $\mathrm{Cr}$-content interdiffusion of $\mathrm{Cr}$ and $\mathrm{Sb}$ starts at low temperatures but is not fully completed before crystallization starts. The metastable phase $\mathrm{Cr}_{1+x} \mathrm{Sb}$ decomposes into stoichiometric $\mathrm{CrSb}$ and nanocrystalline $\mathrm{Cr}$ on further annealing.

The ab-initio electronic structure calculations for perfect NiAs-structure give results on the structure and magnetic properties of $\mathrm{CrSb}$ in line with the experimental data. The corresponding calculations of the structural properties for the $\mathrm{Cr}_{\sim 1.6} \mathrm{Sb}$ and $\mathrm{Cr}_{2} \mathrm{Sb}$ compounds are also in reasonable agreement with experiment. However, the finite DOS at the Fermi level obtained for $\mathrm{Cr}_{\sim 1.6} \mathrm{Sb}$ demonstrate its metallic-like behavior, which contradicts the semiconducting behavior of the resistivity obtained experimentally for this system. Nevertheless, these results allow to make some conclusions concerning to a possible scenario which can bring the system to the state with the energy gap at Fermi level, that will lead to semiconductor-like behavior of the resistivity observed experimentally.

Acknowledgement: The authors thank the financial support of the Deutsche Forschungsgesellschaft (SPP 1415), the state Schleswig-Holstein and Bavaria. We also appreciate the technical support for measurements by Maren Rassmussen and Henning Lühmann, Martin Lammert and Benedikt Flösser as well as Inke Jess and Marlies Schwitzke. Furthermore we thank Dr. Lars Mechold (Laser Components $\mathrm{GmbH}$ ) for the technical and material support.

The co-authors D.C. Johnson and Jeffrey Ditto acknowledge the support from the National Science Foundation through grant DMR-1266217.

\section{References}

[1] A. Kjekshus, K.P. Walseth, Acta Chem. Scand. 23 (1969) 2621-2630.

[2] H. Holseth, A. Kjekshus, Acta Chem. Scand. 22 (1968) 3273-3283.

[3] T.B. Massalski, H. Okamoto, Binary alloy phase diagrams: Cr-Sb (ChromiumAntimony), 2nd ed., ASM International, Materials Park, Ohio, 1990.

[4] T.B. Massalski, H. Okamoto, Binary alloy phase diagrams: Mn-Sb (ManganeseAntimony), 2nd ed., ASM International, Materials Park, Ohio, 1990.

[5] T.B. Massalski, H. Okamoto, Binary alloy phase diagrams: Fe-Sb (Iron-Antimony), 2nd ed., ASM International, Materials Park, Ohio, 1990.

[6] H. Nowotny, R. Funk, J. Pesl, Monatsh. Chem. 82 (1951) 513-525.

[7] B. Grison, P.A. Beck, Acta Cryst. 15 (1962) 807-808. 
[8] T. Chen, J.C. Mikkelsen, G.B. Charlan, J. Cryst. Growth 43 (1978) 5-12.

[9] H. Holseth, A. Kjekshus, Acta Chem. Scand. 22 (1968) 3284-3292.

[10] V.M. Ryzhkovskii, N.D. Zhigadlo, I.L. Pashkovskii, Cryst. Res. Technol. 25 (1990) 165169.

[11] V.S. Goncharov, V.M. Ryzhkovskii, Inorg. Mater. 41 (2005) 557-559.

[12] V.M. Ryzhkovskii, V.S. Goncharov, Inorg. Mater. 46 (2010) 226-231.

[13] R.D. Heyding, L.D. Calvert, Can. J. Chem. 35 (1957) 1205-1215.

[14] B. Bhattacharya, D. Masson, Mater. Sci. Eng. 22 (1976) 133-140.

[15] M. Noh, C.D. Johnson, M.D. Hornbostel, J. Thiel, D.C. Johnson, Chem. Mater. 8 (1996) $1625-1635$.

[16] D.C. Johnson, Current Op. Solid State \& Materials Sc. 3 (1998) 159-167.

[17] F.R. Harris, S. Standridge, C. Feik, D.C. Johnson, Angew. Chem. 115 (2003) 54535457.

[18] R. Atkins, J. Wilson, P. Zschack, C. Grosse, W. Neumann, D.C. Johnson, Chem. Mater. 24 (2012) 4594-4599.

[19] C.L. Heideman, S. Tepfer, Q. Lin, R. Rostek, P. Zschack, M.D. Anderson, I.M. Anderson, D.C. Johnson, J. Am. Chem. Soc. 135 (2013) 11055-11062.

[20] D.B. Moore, M. Beekman, S. Disch, P. Zschack, I. Häusler, W. Neumann, D.C. Johnson, Chem. Mater. 25 (2013) 2404-2409.

[21] M. Regus, G. Kuhn, S. Mankovsky, H. Ebert, W. Bensch, J. Solid State Chem. 196 (2012) 100-109.

[22] J.R. Williams, M. Johnson, D.C. Johnson, J. Am. Chem. Soc. 123 (2001) 1645-1649.

[23] A. Smalley, M.L. Jespersen, D.C. Johnson, Inorg. Chem. 43 (2004) 2486-2490.

[24] J.R. Williams, D.C. Johnson, Inorg. Chem. 41 (2002) 4127-4130.

[25] R. Schneidmiller, M.D. Hornbostel, D.C. Johnson, Inorg. Chem. 36 (1997) 5894-5899.

[26] S. Kraschinski, S. Herzog, W. Bensch, Solid State Sci. 4 (2002) 1237-1243.

[27] S. Herzog, S. Kraschinski, W. Bensch, Z. Anorg. Allg. Chem. 629 (2003) 1825-1832.

[28] M. Behrens, R. Kiebach, W. Bensch, D. Häußler, W. Jäger, Inorg. Chem. 45 (2006) 2704-2712.

[29] M. Regus, G. Kuhn, S. Polesya, S. Mankovsky, M. Alemayehu, M. Stolt, D.C. Johnson, H. Ebert, W. Bensch, Z. Kristallogr. 229 (2014) 505-515.

[30] M.D. Anderson, J.O. Thompson, D.C. Johnson, Chem. Mater. 25 (2013) 3996-4002.

[31] A. Coelho, Topas Academic: Coelho Software, Brisbane, Australien.

[32] L.B. McCusker, Von Dreele, R. B., D.E. Cox, D. Louër, P. Scardi, J. Appl. Cryst. 32 (1999) 36-50.

[33] R.W. Cheary, A. Coelho, J. Appl. Cryst. 25 (1992) 109-121.

[34] M. Järvinen, J. Appl. Cryst. 26 (1993) 525-531.

[35] D. Balzar, N. Audebrand, M.R. Daymond, A. Fitch, A. Hewat, J.I. Langford, A. Le Bail, D. Louër, O. Masson, C.N. McCowan, N.C. Popa, P.W. Stephens, B.H. Toby, J. Appl. Cryst. 37 (2004) 911-924. 
[36] O. Boffoué, A. Jacquot, A. Dauscher, B. Lenoir, M. Stölzer, Rev. Sci. Instrum. 76 (2005) 053907.

[37] H. Ebert, D. Ködderitzsch, J. Minár, Rep. Prog. Phys. 74 (2011) 096501.

[38] H. Ebert et al., SPR-KKR: The Munich SPR-KKR package, München, 2009.

[39] J.P. Perdew, K. Burke, M. Ernzerhof, Phys. Rev. Lett. 77 (1996) 3865-3868.

[40] A.I. Liechtenstein, M.I. Katsnelson, V.P. Antropov, V.A. Gubanov, J. Magn. Magn. Mater. 67 (1987) 65-74.

[41] N. Zotov, A. Ludwig, Mater. Sci. Eng., C 27 (2007) 1470-1474.

[42] J.H. Sharp, G.W. Bringley, Narahari Achar, B. N., J. Am. Ceram. Soc. 49 (1966) 379382.

[43] M. Avrami, J. Chem. Phys. 7 (1939) 1103-1112.

[44] M. Avrami, J. Chem. Phys. 8 (1940) 212-224.

[45] M. Avrami, J. Chem. Phys. 9 (1941) 177-184.

[46] N.P. Grazhdankina, L.A. Matyushenko, Y.S. Bersenev, Fizika Tverdogo Tela 10 (1968) 670-677.

[47] H.J. Hrostowski, F.J. Morin, T.H. Geballe, G.H. Wheatley, Phys. Rev. 100 (1955) 1672 1676.

[48] I.G. Fakidov, A.Y. Afanas'ev, Fizika Metallov i Metallovedenie 6 (1958) 176-177.

[49] Z. Aabdin, N. Peranio, M. Winkler, D. Bessas, J. König, R.P. Hermann, H. Böttner, O. Eibl, J. Electron. Mater. 41 (2012) 1493-1497.

[50] Willis, B. T. M., Acta Cryst. 6 (1953) 425-426.

[51] S. Polesya, G. Kuhn, S. Mankovsky, H. Ebert, M. Regus, W. Bensch, J. Phys.: Condens. Matter 24 (2012) 036004(1-5). 


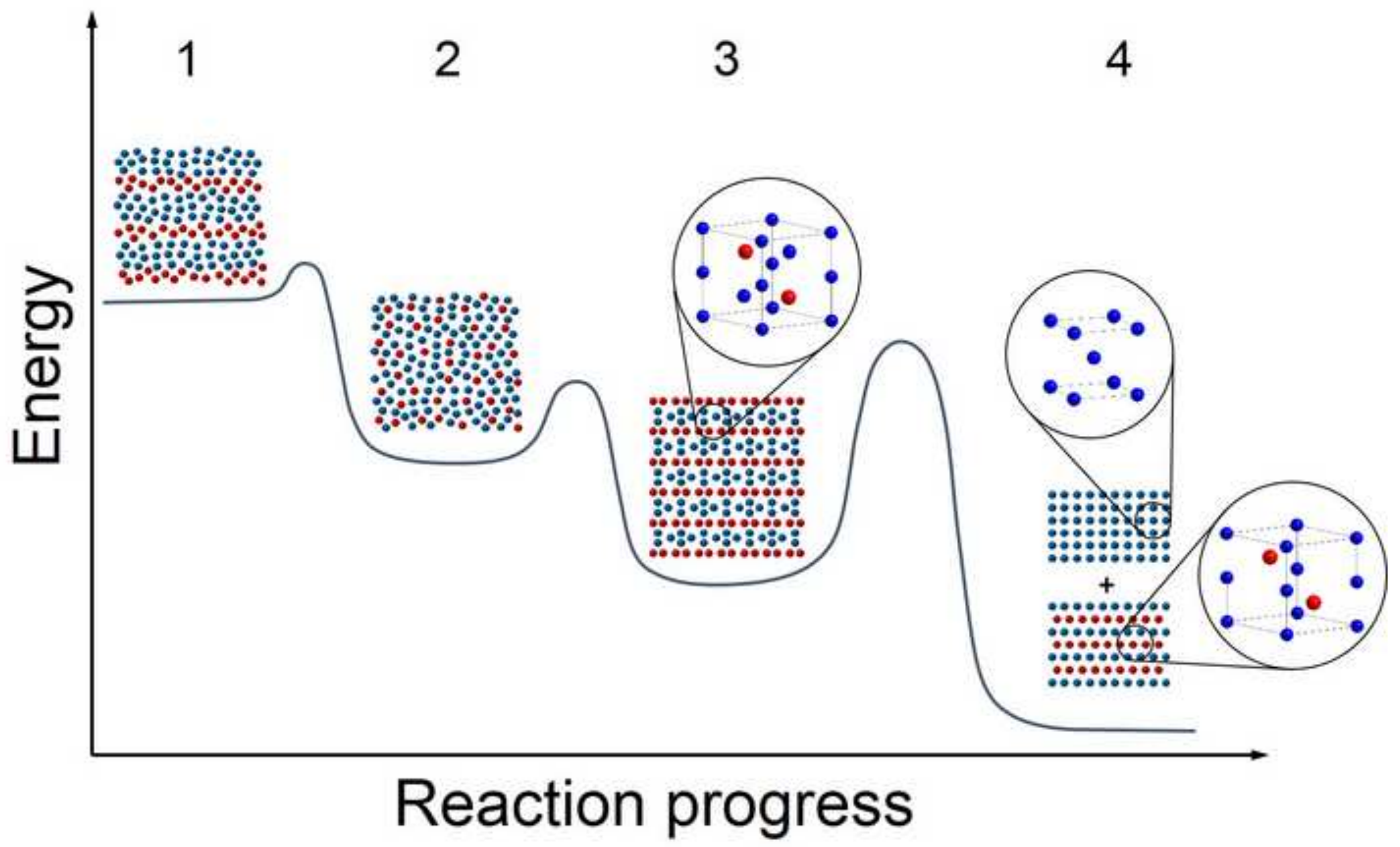


Title: Characterization of Cr-rich Cr-Sb Multilayer Films: Syntheses of a New Metastable Phase Using Modulated Elemental Reactants

Authors: Matthias Regus, Sergiy Mankovsky, Svetlana Polesya, Gerhard Kuhn, Jeffrey Ditto, Ulrich Schürmann, Alexandre Jacquot, Kilian Bartholomé, Christian Näther, Markus Winkler, Jan D. König, Harald Böttner, Lorenz Kienle, David C. Johnson, Hubert Ebert, Wolfgang Bensch

Pages: $30 \mathrm{p}$.

Legend: 1 amorphous multilayered film

2 interdiffused amorphous film

3 metastable crystalline phase

4 thermodynamic stable phase (and by-product) 